\title{
From the Sun to the Earth: impact of the 27-28 May 2003 solar events on the magnetosphere, ionosphere and thermosphere
}

\author{
C. Hanuise ${ }^{1}$, J. C. Cerisier ${ }^{2}$, F. Auchère ${ }^{3}$, K. Bocchialini ${ }^{3}$, S. Bruinsma ${ }^{4}$, N. Cornilleau-Wehrlin ${ }^{5}$, N. Jakowski ${ }^{6}$, \\ C. Lathuillère ${ }^{7}$, M. Menvielle ${ }^{2}$, J.-J. Valette ${ }^{8}$, N. Vilmer $^{9}$, J. Watermann ${ }^{10}$, and P. Yaya ${ }^{8}$ \\ ${ }^{1}$ LPCE/CNRS, 3A avenue de la Recherche Scientifique, 45071 Orléans Cedex, France \\ ${ }^{2}$ CETP/CNRS, 4 avenue de Neptune, 94107 St Maur des Fossés Cedex, France \\ ${ }^{3}$ IAS, Bâtiment 121, Université Paris Sud 11 - CNRS, 91405 Orsay Cedex, France \\ ${ }^{4}$ CNES, Département de Géodésie Spatiale, 31055 Toulouse Cedex 4, France \\ ${ }^{5}$ CETP/IPSL, 10-12 avenue de l'Europe, 78140 Vélizy-Villacoublay, France \\ ${ }^{6}$ Deutsches Zentrum für Luft und Raumfahrt, Kalkhorstweg 53, 17235 Neustrelitz, Germany \\ ${ }^{7}$ LPG, Bâtiment D de Physique, BP 53, 38041 St Martin d'Hères Cedex 9, France \\ ${ }^{8}$ CLS, 8 - 10 rue Hermès, 31520 Ramonville Saint-Agne, France \\ ${ }^{9}$ LESIA, Observatoire de Paris, 5 place Jules Jansen, 92195 Meudon Cedex, France \\ ${ }^{10}$ Danish Meteorological Institute, Lyngbyvej 100, 2100 Copenhagen, Denmark
}

Received: 23 February 2005 - Revised: 10 October 2005 - Accepted: 18 November 2005 - Published: 7 March 2006

\begin{abstract}
During the last week of May 2003, the solar active region AR 10365 produced a large number of flares, several of which were accompanied by Coronal Mass Ejections (CME). Specifically on 27 and 28 May three halo CMEs were observed which had a significant impact on geospace. On 29 May, upon their arrival at the L1 point, in front of the Earth's magnetosphere, two interplanetary shocks and two additional solar wind pressure pulses were recorded by the ACE spacecraft. The interplanetary magnetic field data showed the clear signature of a magnetic cloud passing ACE. In the wake of the successive increases in solar wind pressure, the magnetosphere became strongly compressed and the sub-solar magnetopause moved inside five Earth radii. At low altitudes the increased energy input to the magnetosphere was responsible for a substantial enhancement of Region-1 field-aligned currents. The ionospheric Hall currents also intensified and the entire high-latitude current system moved equatorward by about $10^{\circ}$. Several substorms occurred during this period, some of them - but not all apparently triggered by the solar wind pressure pulses. The storm's most notable consequences on geospace, including space weather effects, were (1) the expansion of the auroral oval, and aurorae seen at mid latitudes, (2) the significant modification of the total electron content in the sunlight highlatitude ionosphere, (3) the perturbation of radio-wave propagation manifested by HF blackouts and increased GPS signal scintillation, and (4) the heating of the thermosphere, causing
\end{abstract}

Correspondence to: C. Hanuise

(christian.hanuise@cnrs-orleans.fr) increased satellite drag. We discuss the reasons why the May 2003 storm is less intense than the October-November 2003 storms, although several indicators reach similar intensities.

Keywords. Interplanetary physics (Solar wind plasma) Magnetospheric physics (Magnetosphere-ionosphere interactions), Ionosphere (Ionosphere-atmosphere interactions)

\section{Introduction}

Geospace is at all times affected by the solar wind, a supersonic plasma stream emerging from the Sun. Besides largescale recurrent structures (such as the interplanetary magnetic field sector and solar wind flow regime boundaries), eruptive solar events of high intensity, predominantly solar flares resulting in halo Coronal Mass Ejections (CMEs) and solar energetic particle emissions, can have a significant impact on geospace. The vast majority of the very intense storms were observed to be associated with interplanetary CMEs (ICMEs) and shocks passing by the Earth (Tsurutani and Gonzalez, 1997). They are an interplanetary manifestation of earthward directed CMEs. If the Earth is in a favourable position with respect to the solar source of a CME, it may deposit large amounts of energy in the Earth's magnetosphere. A part of it is released immediately while another part is stored in the magnetosphere and released later.

Such solar events follow a causal chain in the sense that there is always a solar source where the disturbances originate and from where they propagate through interplanetary space and eventually interact with the Earth's magnetosphere 


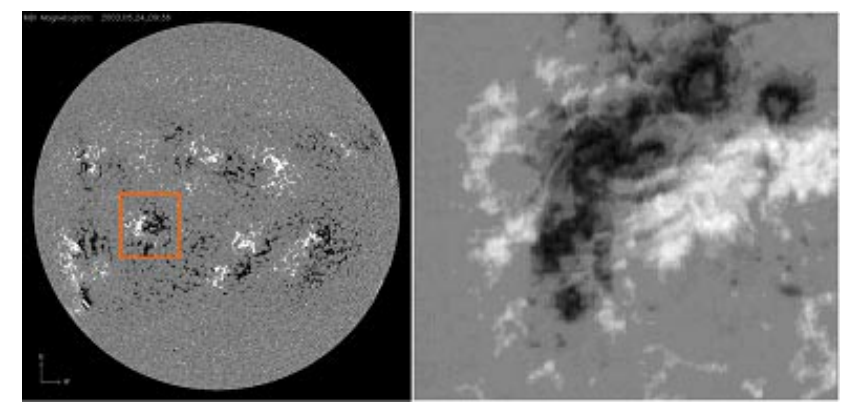

Fig. 1. Left: Magnetogram of the solar disk obtained with MDI/SOHO on 24 May 2003 at 9:36 UT. Active Region AR 10365 is indicated by the orange square. Right: $140 \times 110 \operatorname{arcsec}^{2}$ image centred on AR 10365 observed with THEMIS on 27 May at 06:58 UT in Fe I 630.2 nm.

to initiate magnetospheric and ionospheric storms. After propagation through the interplanetary space, it is the configuration of the solar wind plasma (density and bulk velocity) and magnetic field (intensity and direction) at the Earth's location which determines the strength of the interaction with the magnetosphere. The consequences of such storms can be noticed immediately (e.g. auroral displays, large variations of the geomagnetic field) and may adversely affect humans and technological systems (e.g. enhanced radiation, disturbed radio wave propagation). However, the various links of this chain - from the Sun to the resulting space weather effects - are often treated separately and independently, due to the fact that they fall into the realms of different research communities.

In this paper, we make an attempt to study the entire chain for a short sequence of individual (though complex) solar and geospace events. To do so we have selected the 27-30 May 2003 space storm period during the declining phase of solar cycle 23 , which was characterized by numerous solar flares and several Earth directed CMEs, resulting in an "intense geomagnetic storm" (minimum $D_{s t}=-131 \mathrm{nT}$ ), according to the classification of Gonzalez et al. (1994).

We give a comprehensive description of the physical processes associated with this period of solar activity, starting with the energy release at the solar surface and ending with the energy deposition in geospace and the associated space weather effects on technological systems. To do so, it proves to be essential to collect data from a number of platforms, notably the SOHO and ACE spacecraft at the L1 point, as well as the GOES and CLUSTER satellites, but also from a number of ground-based observatories and other measurement sites. The May activity occurred during the 11th MEDOC (Multi-Experiment Data and Operation Centre) campaign, during which intensive $\mathrm{SOHO}$ observations were undertaken in coordination with the EISCAT/ESR and SuperDARN radars.

Section 2 deals with the solar activity observed during the 26-28 May period when the active region AR 10365 was the source of several X class flares and associated CMEs. Section 3 first summarizes solar wind conditions as observed

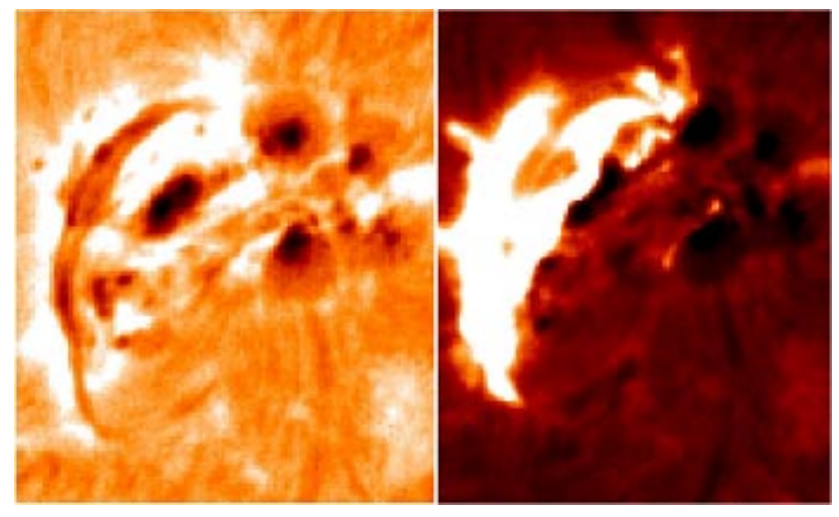

Fig. 2. Left: $\mathrm{H} \alpha$ image of $\mathrm{AR} 10365$ on 27 May 2003 at 22:46:26 UT; $15 \mathrm{~min}$ before the first observation of the CME. Filament and pores are visible. The field of view is $250 \times 300 \mathrm{arcsec}^{2}$. Right: Same field of view at 23:06:26 UT, at the appearance of the flare; the filament has disappeared (images from Big Bear Solar Observatory).

by ACE before analysing the propagation of the halo CMEs through the interplanetary medium. In Sect. 4, the global impact of the CMEs on the magnetosphere is evaluated, both through its compression by the increased solar wind pressure and through the increased energy input which occurred mainly during the periods of large southward interplanetary magnetic field (IMF), favouring reconnection at the magnetopause. The electrodynamic response of the coupled magnetosphere-ionosphere system to the various phases of the storm is described in Sect. 5, based on magnetic (the latitudinal chains in Greenland and Scandinavia and magnetic indices) and incoherent scatter radar (EISCAT) measurements. Thereafter, we focus in Sect. 6 on the consequences of the storm on the neutral and ionized components of the atmosphere (thermosphere and ionosphere, respectively). We conclude the description of the event in Sect. 7 with a more practically oriented assessment of several of the storm effects on the near-Earth environment (space weather effects), with emphasis placed on the absorption of High Frequency (HF) waves in the lower ionosphere, the perturbation of low-altitude satellite orbits due to increased atmospheric drag and ionospheric scintillations in the radio signals of the Global Positioning System (GPS) due to plasma turbulence. Finally Sect. 8 discusses the observations in a comparative context with the larger storms of the October (Halloween) and November 2003 periods.

\section{The solar Active Region AR 10365}

The combination of ground-based and space-borne solar observations provides the opportunity to follow the time evolution of the active region AR 10365 from the photosphere up to the corona. According to NOAA/SEC reports, more than 30 flares occurred in AR 10365 from 26 May at 00:00 UT until 29 May at 00:00 UT; the magnetic fluxes increased and reached their maximum on 28 May $\left(1.2 \times 10^{14} \mathrm{Tesla} \mathrm{m}^{2}\right.$ on 

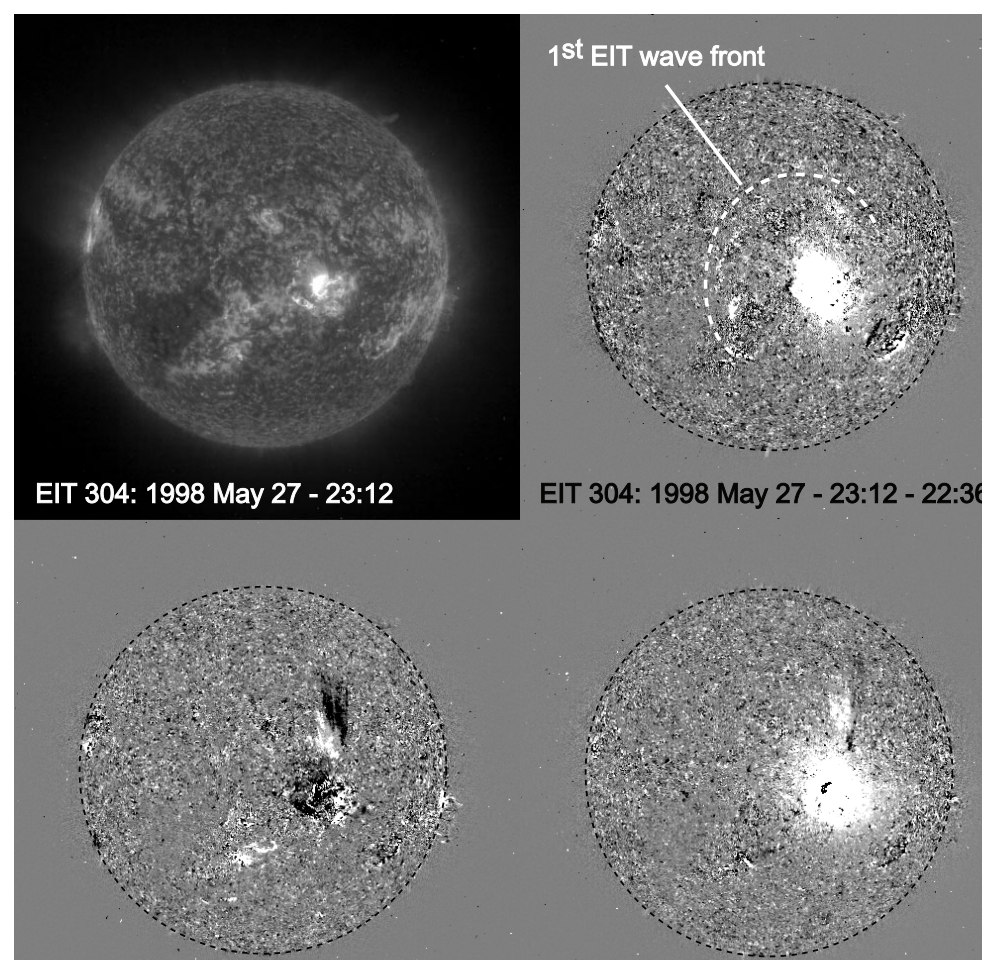

EIT 304: 1998 May $27-23: 12-22: 36$

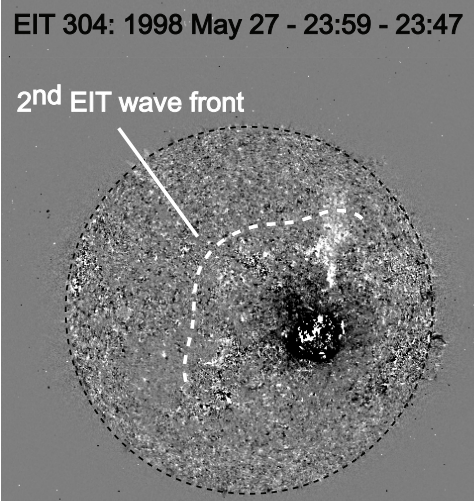

EIT 304: 1998 May 28 - 00:36 - 00:24

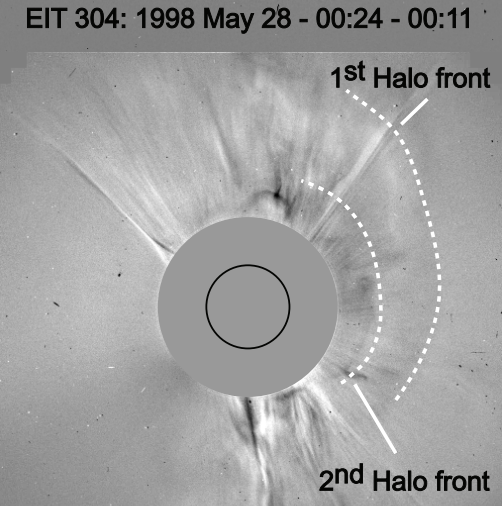

LASCO C2: 1998 May 28 - 00:50 - 00:42

Fig. 3. SOHO observations. The top left image is the Sun seen by EIT in the $30.4 \mathrm{~nm}$ line of He II. AR 10365 is defined by the strong intensity enhancement. The 4 following images are EIT running difference at $30.4 \mathrm{~nm}$ (He II); the first flare is detected by EIT at 23:12 UT on 27 May 2003 (top right), and the second at 00:24 UT on 28 May 2003 (centre right). The centre left image shows a black and white structure at the north of the AR: this is the signature of the ejected filament seen on Fig. 2. On the bottom left and top right images, the white dotted lines indicate the circular front propagating from the centre of the AR, and associated to EIT waves seen in projection on the solar disk. The bottom right image shows the 2 halo CMEs seen by LASCO-C2/SOHO on 28 May between 00:50 UT and 00:42 UT (running difference). The position of the Sun is indicated by the black circle. The grey disk is the mask of the coronagraph occulting the Sun.

the average), i.e. 4.5 days after the emerging flux birth (Chae et al., 2004). These authors suggest that the largest flare explosion may have been related to the accumulation of magnetic helicity in the corona and noted that "the strongest flare occurred after the rate of helicity injection peaked".

At the photospheric level, MDI/SOHO (Scherrer et al., 1995) magnetograms obtained between 20 May and 29 May 2003 showed a complex magnetic structure in AR 10365 (indicated by an orange square in Fig. 1, left panel), with several inversion lines. This complex structure is confirmed by the high resolution magnetogram obtained in the Fe I line at $630.2 \mathrm{~nm}$ at the THEMIS observatory on 27 May at 06:58 UT (Fig. 1, right). MDI magnetograms show an emerging flux which appeared on 24 May around 09:36 UT, east of the active region, and grew until it became as large as the initial active region itself.

At the chromospheric level, an $\mathrm{H} \alpha$ image obtained on 27 May at 22:46 UT from Big Bear Solar Observatory reveals a few small black circular structures known as pores (also seen on Fig. 1, right) and a black elongated structure on 
Table 1. Characteristics of the 3 halo CMEs observed on 27-28 May 2003.

\begin{tabular}{llll}
\hline & CME 1 & CME 2 & CME 3 \\
\hline Date / Time & May 27, 2003 @ 06:50 UT & May 27, 2003 @ 23:50 UT & May 28, 2003 @ 00:50 UT \\
Speed $\left(^{*}\right)$ & 509 km/s & $960 \mathrm{~km} / \mathrm{s}$ & $1370 \mathrm{~km} / \mathrm{s}$ \\
Associated Flare & M1.6 @ 06:26 UT & X1.3 @23:07 UT & X3.6 @00:27 UT \\
\hline
\end{tabular}

(*) speed estimates at 20 Rs derived from the measurements of the CMEs by $\mathrm{C} 2$ and $\mathrm{C} 3$ coronagraphs

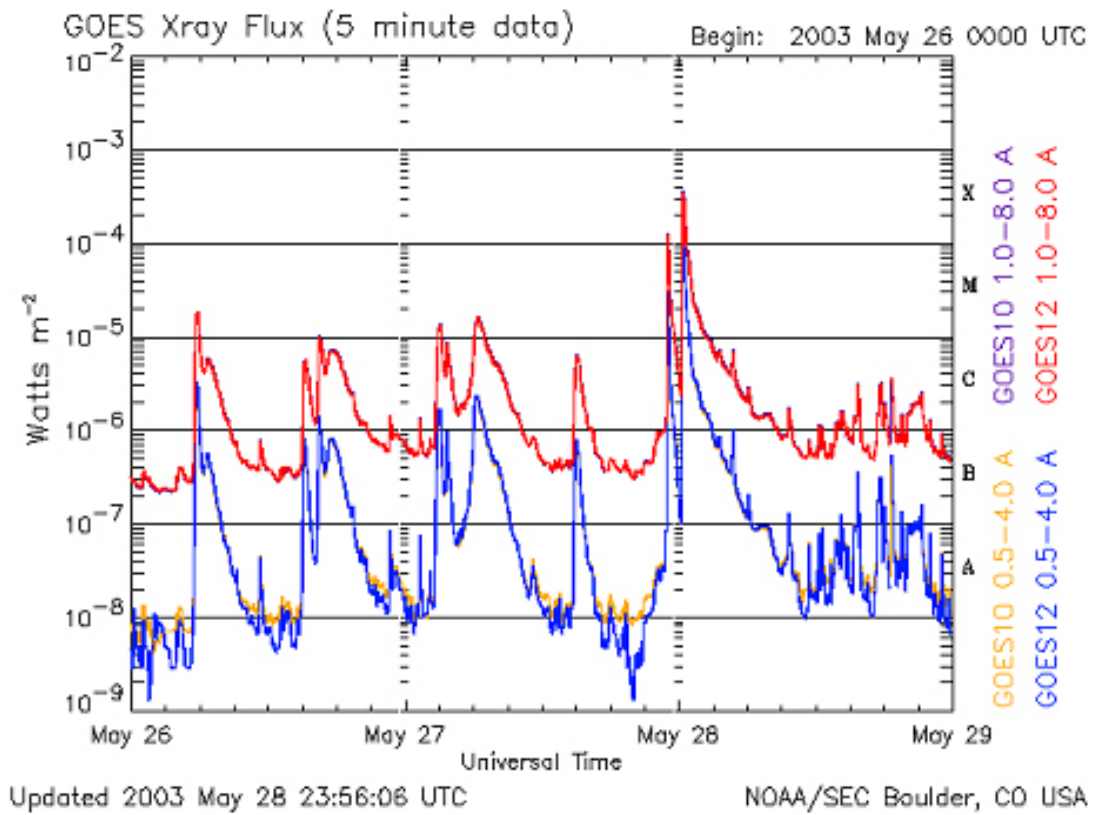

Fig. 4. X-ray flux recorded by GOES between 26 May 00:00 UT and 29 May 00:00 UT: two peaks of x-ray flux occur on 27 May around 23:10 and on 28 May around 00:30 UT, respectively.

the left which could be an active filament (Fig. 2, left). Figure 2 (right) shows the active region at 23:05 UT at its intensity maximum, probably indicating the beginning of the X1.2 flare observed at 23:10 UT by the GOES-10 and GOES-12 satellites.

On 27-29 May 2003 the EUV Imaging Telescope (EIT, Delaboudinière et al., 1995) on board SOHO was in "CME watch" mode (12-min cadence), in the 30.4-nm line of He II (formed in the chromosphere to corona transition region at $0.8 \mathrm{MK}$ ). This mode allows the observation of the initial phase of CMEs. The CMEs are initiated in association with flares and/or prominences/ filament ejections (Delannée et al., 2000), and are the consequence of global instabilities of the magnetic field (Schmieder et al., 2002). The "CME watch" mode is usually operated in the $19.5-\mathrm{nm}$ wavelength band of Fe XII (formed in the hot corona at 1.5 MK). Thompson et al. (1999) analysed EIT image differences in Fe XII and showed, for the first time, waves in expansion from the initiation site of the halo CME. These waves are a signature of halo CMEs and represent globally propagating coronal disturbances which emanate from a central radial point and travel across the visible solar surface (Gilbert et al., 2004). In their MHD simulations, Chen et al. (2005) demonstrate that EIT waves are thought to be formed by successive stretching or opening of closed field lines driven by an erupting flux rope: "during the stretching process, the plasma on the outer side of the field line is compressed to form the densityenhanced EIT wave front, while inside the field line, the plasma is evacuated to form a dimming region due to the expansion". The propagation speed of the waves is typically around $250 \mathrm{~km} / \mathrm{s}$ but has been observed to reach $800 \mathrm{~km} / \mathrm{s}$ (Zhukov and Auchère, 2004). The relations between flares, prominence ejections and CMEs are, however, difficult to establish observationally.

The He II movie for 27-29 May 2003 shows two successive intensity enhancements (flare signature) in AR 10365 at 23:12 UT on 27 May and at 00:24 UT on 28 May 2003. In the former case the flux increase is about $15 \%$ but due to telemetry limitations, the very beginning of the CME at 23:10 UT was not recorded; in the latter the flux increase is about $20 \%$. Simultaneously with the first enhancement, the filament described in the $\mathrm{H} \alpha$ image in Fig. 2 is ejected in the northwest direction (projected on the disk), and appears as dark material absorbing the He II radiation. Figure 3 


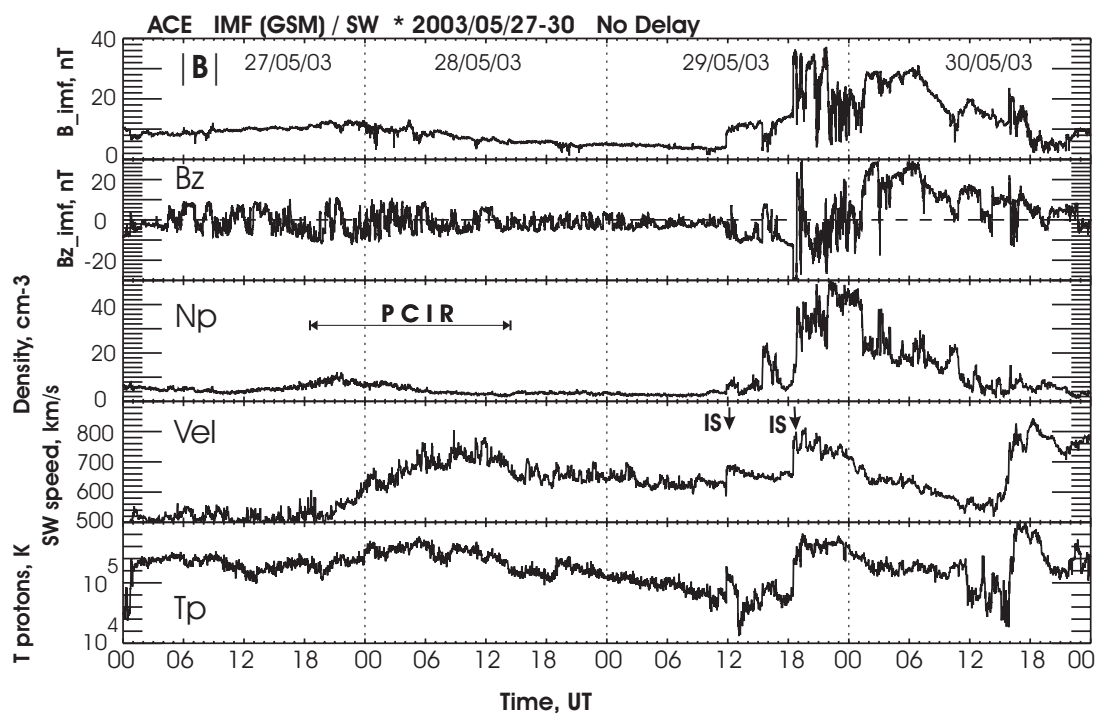

Fig. 5. IMF and solar wind parameters at L1 for the period 27-30 May 2003 recorded by the ACE spacecraft.

contains a series of running difference images in He II. On images 2 to 5 , we clearly see the cold ejected material (black and white structure) coming from the erupting filament, at the top of AR 10365. After each flare, we can see the progression of a faint halo, centred on the AR and associated with waves, the disk projection of which were observed by EIT; in both cases, the circular wave fronts are propagating at an exceptionally large speed of $1000 \mathrm{~km} / \mathrm{s}$, larger than the usual EIT waves. Signatures of the events described above were also recorded by the Large Angle and Spectrometric Coronograph (LASCO) on board SOHO. The list of CMEs observed by LASCO (Brueckner et al., 1995) and published at http://cdaw.gsfc.nasa.gov/CME_list/ shows that up to ten CMEs were observed with the $\mathrm{C} 2$ coronagraph between 01:50 UT on 27 May and 00:50 UT on 28 May. As described, for example, in Vilmer et al. (2003), halo CMEs have a higher probability to reach the Earth's orbit. Table 1 gives the time of appearance of the three 27 May-28 May halo CMEs observed in $\mathrm{C} 2$, their estimated speed and the associated flares, as observed by GOES (Fig. 4). In the following sections, we determine the signatures and investigate the effects of these 3 halo CMEs in geospace.

\section{Solar wind/interplanetary conditions}

ACE observations at L1 for the period 27 May to 30 May are shown in Fig. 5. The perturbed period started to be observed by ACE in the evening of 27 May when a Pseudo Corotating Interaction Region (PCIR) (Tsurutani et al., 1995; Gonzalez et al., 1999) was observed, as indicated by (i) a smooth solar wind density increase followed by a decrease from a maximum of $10 \mathrm{~cm}^{-3}$ at 21:30 UT on $27 \mathrm{May}$, (ii) a solar wind velocity maximum larger than $600 \mathrm{~km} / \mathrm{s}$ around 10:00 UT, and (iii) a solar wind temperature increase up to $5 \times 10^{5} \mathrm{~K}$. The PCIR is probably the signature of the Earth entering a coronal hole stream which is characterized by enhanced background solar wind speed. It was followed, on 29 May, by the arrival of two interplanetary shocks (IP), as indicated by vertical arrows in Fig. 5, shortly before noon and around 18:30 UT. In each of these shocks, the density and the bulk velocity of the solar wind increase substantially, up to $40 \mathrm{~cm}^{-3}$ and $800 \mathrm{~km} / \mathrm{s}$ after the second shock.

The interplanetary magnetic field displays a complex structure. After each of the two shocks, the IMF exhibits one classical magnetic cloud behaviour with an increase in the amplitude and an inversion of $B z$ usually attributed to a flux rope structure. The minimum $B z$ reaches $-30 \mathrm{nT}$ at the arrival of the second shock. Later, $B z$ retreats to less extreme values before turning northward in the early hours of 30 May.

The magnetic clouds and shocks are now related to their solar origin (CMEs and flares), using the procedure described in Vilmer et al. (2003). An early limit to the launch time is estimated assuming that the interplanetary perturbation propagates with a constant velocity, given by the value measured at 1 AU. Shortly after the first shock, the velocity is of the order of $700 \mathrm{~km} / \mathrm{s}$, leading to a transit time of two days and ten hours from the Sun to ACE. The launch window thus starts at 01:50 UT on 27 May. It is very likely that the first interplanetary CME (ICME) is associated with the first halo CME at 06:50 UT (transit time of two days and five hours), and that the second shock and subsequent magnetic cloud is associated with a combination of the two very fast halo CMEs, with the later one probably catching up with the earlier one. This is consistent with previous findings for a series of interplanetary perturbations and a series of fast halo CMEs (Vilmer et al., 2003). As suggested in previous studies, the perturbation does not propagate with a constant speed between the Sun and the Earth (Gopalswamy et al., 2000; St. Cyr et al., 2000). CMEs are likely to interact with the often-slower ambient solar wind. It is thus expected and it has been observed that the speed of most ICMEs has decreased down to that of the 

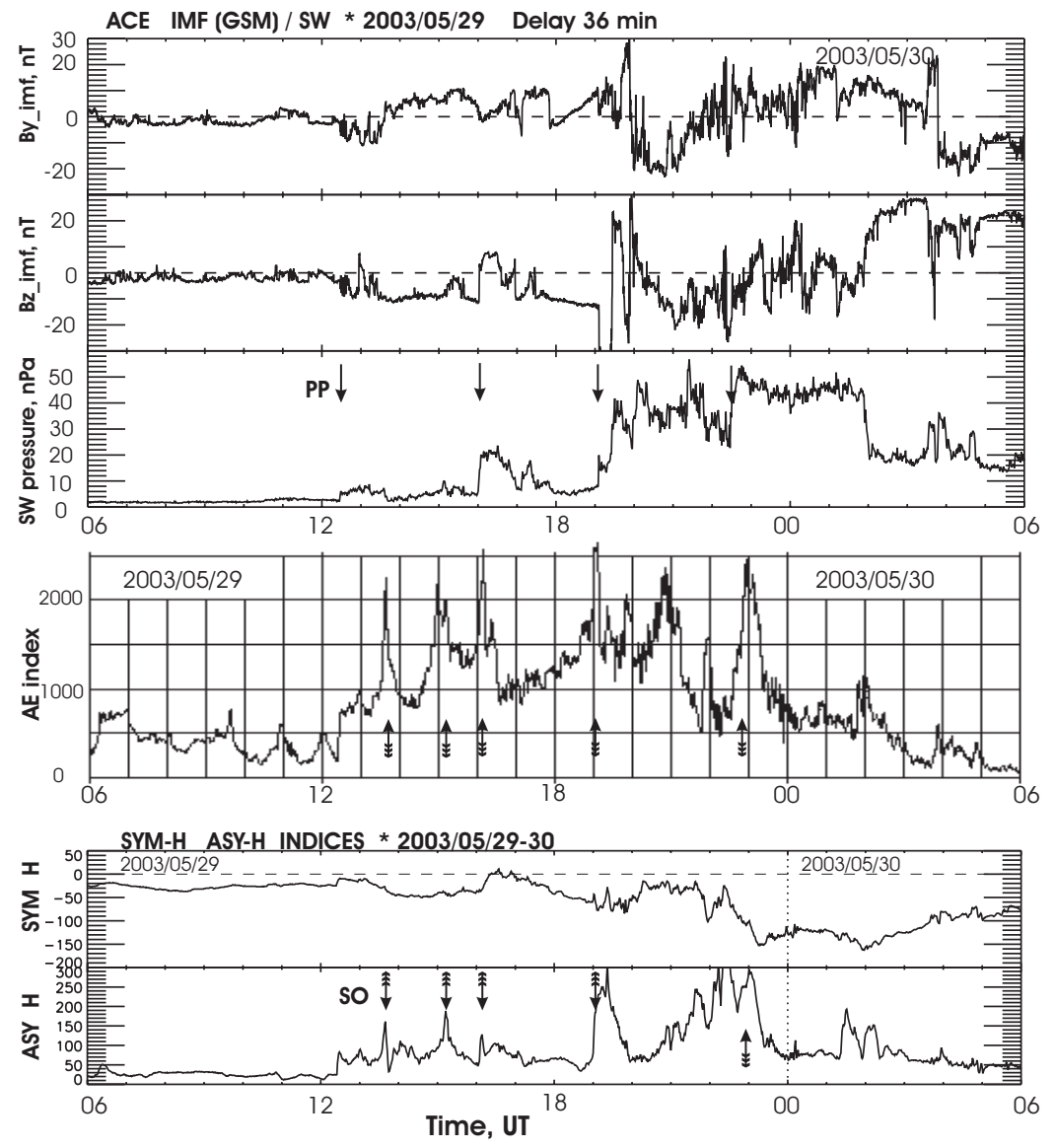

Fig. 6. Characterization of the main phase of the magnetic storm. Top: IMF and solar wind pressure derived from ACE observations. Time is delayed by $36 \mathrm{~min}$ in order to match magnetospheric data. Centre: Auroral Electrojet $(A E)$ index. Bottom: SYM-H and ASY-H indices.

solar wind at the ACE location. This appears to be the case for the two fast halo CMEs of 27-28 May.

\section{Solar wind - magnetosphere coupling}

Let us now focus on the period following the arrival of the first shock around 12:00 UT on 29 May. ACE data for the 30-h period starting on 29 May at 06:00 UT are displayed in Fig. 6 (upper panel). The measured solar wind speed suggests that the delay from ACE to the dayside magnetosphere boundary varies between 33 and 41 min during that period. Thus, for easier comparison with magnetospheric data, the ACE data in Fig. 5 have been delayed by a mean transit time to the magnetosphere of $36 \mathrm{~min}$. We will refer to this delayed time further in this paper.

During the initial period of the magnetic cloud passage, from 12:28 UT on 29 May until 01:53 UT on 30 May, the IMF $B z$ is negative (with several short positive excursions), reaching a minimum value of $-32 \mathrm{nT}$ after 19:00 UT. In addition to the two interplanetary shocks mentioned in the previous section, which are assumed to have arrived at the magnetopause at 12:28 UT and 19:06 UT, respectively, the solar wind pressure shows two increases associated with density jumps at 16:00 UT and 22:30 UT (estimated arrival).
These four dynamic pressure pulses (PP as indicated by vertical arrows) are responsible for the sudden impulses or storm sudden commencements (SSC) recorded by various ground magnetometers. The second shock (third pulse) is followed by a long period (about $7 \mathrm{~h}$ ) of very high pressure (oscillating between 30 and 50 nP). At 01:53 UT on 30 May, the IMF $B z$ turns positive and persists.

\subsection{Magnetosphere compression}

The influence of the solar wind pressure changes on the size of the magnetosphere can be inferred from GOES-10/12 and Cluster observations. Energetic particle and magnetic field measurements aboard GOES-10 and GOES-12 indicate that the magnetopause moved inside the geosynchronous orbit at 19:00 UT on 29 May upon the arrival of the second interplanetary shock. Later, Cluster, on its inbound path, left the magnetosheath and entered the compressed magnetosphere in the early morning sector, as indicated by characteristic changes in the dynamic frequency spectra of the magnetic ULF turbulence and of the magnetic field component perpendicular to the spin plane (Fig. 7, top panels from the STAFF experiment, Cornilleau-Wehrlin et al., 2003). The magnetosheath populated by solar wind shocked particles is 


\section{CLUSTER/STAFF-SC Bz Log Power Spectral Density $(\mathrm{nT}$ 2//Hz)}
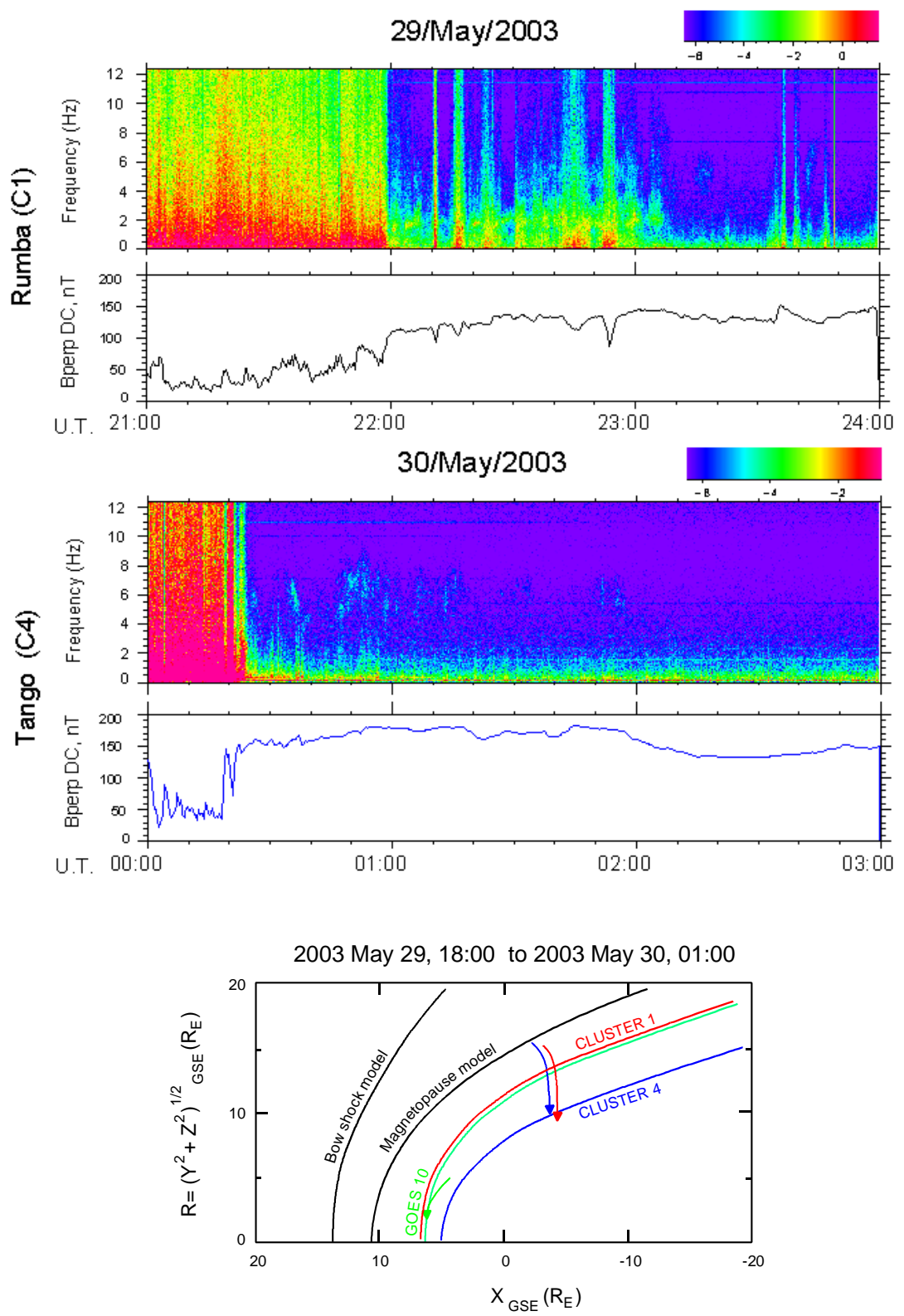

Fig. 7. Magnetopause crossings observed by different spacecraft. Top panels: Cluster-STAFF ULF dynamic spectra and magnetic field modulus in the spin plane around magnetopause crossings for spacecraft 1 and 4 . The lower panel shows the orbit of GOES 10, CLUSTER 1 and CLUSTER 4 in $x,\left(y^{2}+z^{2}\right)^{1 / 2}$ GSE coordinates for the 18:00-01:00 UT time interval. The orbits are represented by the green, red and blue arrows, respectively. The magnetopause position deduced from its crossing by those 3 spacecraft is drawn with the same colour code (see Table 2). The mean magnetopause and bow shock for quiet solar wind conditions $\left(\mathrm{P}_{S W}=2.1 \mathrm{nPa}\right.$, IMF $\left.B z=0\right)$ are shown in black for comparison.

characterized by intense, quasi-permanent, ULF, broad-band emissions, whereas only weak, quasi-monochromatic emissions are observed in the outer magnetosphere. A sudden decrease in the electron flux intensity in the sub- $\mathrm{KeV}$ energy range (typical magnetosheath population) confirms the entrance of Cluster into the outer magnetosphere (PEACE experiment, Johnstone et al., 1997; D. Fontaine, private communication). According to the magnetopause model used for orbit prediction under moderate solar wind conditions (pressure $=2.1 \mathrm{nP}, \mathrm{IMF} B z=0$ ), Cluster 1, which was the most earthward of the four spacecraft, should have entered the magnetosphere on the dawn side around 12:00 UT on its inbound path. However, it remained in the magnetosheath up to 22:00 UT and even made two excursions into the unshocked solar wind. Cluster 1, 2 and 4 entered the magnetosphere at 22:00 UT on 29 May and at 00:12 UT and 00:20 UT on 30 May, respectively, as shown on Fig. 7 (bottom panel, only spacecraft 1 and 4). 
Table 2. Location of the magnetopause crossings and estimated radial distance of the subsolar point according to the model of Sibeck et al. (1991).

\begin{tabular}{ccccccc}
\hline Satellite & date & UT & $\mathrm{X}(\mathrm{R} / \mathrm{Re})$ & $\mathrm{Y}(\mathrm{R} / \mathrm{Re})$ & $\mathrm{Z}(\mathrm{R} / \mathrm{Re})$ & d_sibeck(Re) \\
\hline GOES 10 & $29 / 05 / 2003$ & $19: 00$ & 5.49 & -3.14 & 0.94 & 6.3 \\
C1 & $29 / 05 / 2003$ & $22: 00$ & -3.47 & -4.84 & -9.59 & 6.6 \\
C2 & $30 / 05 / 2003$ & $00: 12$ & -2.67 & -1.29 & -8.15 & 5.1 \\
C4 & $30 / 05 / 2003$ & $00: 20$ & -3.05 & -2.30 & -8.05 & 5.0
\end{tabular}

CHAMP Region 1 currents * 2003/05/29 1500-1600 MLT

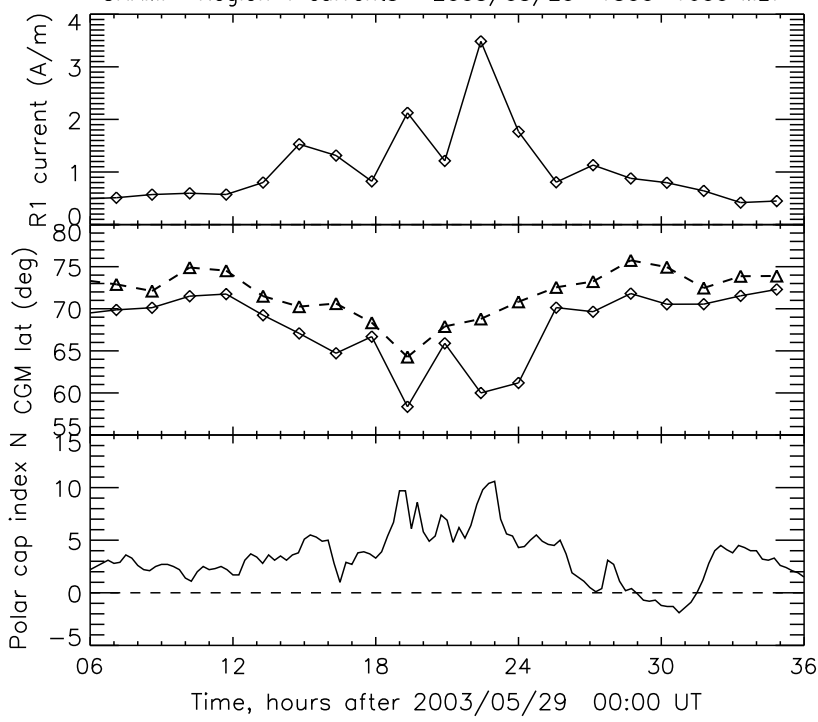

Fig. 8. R-1 current in the 15:00-16:00 MLT sector derived from CHAMP magnetometer data. Top: Current intensity (latitudinally integrated current density). Centre: Latitudinal position of the equatorward (solid) and poleward (dashed) boundaries of the R-1 current sheet. Bottom: Polar Cap North $(P C N)$ index.

From the measured location of the magnetopause crossing, it is possible to derive the geocentric distance of the magnetopause subsolar point with the help of the Sibeck et al. (1991) model. The values are given in the last column of Table 2. It is obvious that the compression has increased with time. The estimated subsolar distance was close to $6.5 R_{E}$ (Earth radii) around 19:00 and 22:00 UT on 29 May and $5 R_{E}$ at 00:20 UT on 30 May, in response to the corresponding increase in the solar wind pressure. The bottom panel of Fig. 7 displays the orbits of Cluster 1 and 4 and GOES-10, together with the position of the magnetopause inferred from the crossing times and from the Sibeck et al. (1991) model.

\subsection{Energy input to the magnetosphere}

Several indicators of the coupling of the interplanetary medium with the magnetosphere have been proposed (Gonzalez et al., 1989 and references therein). Computed from solar wind parameters, generally observed at L1, they aim at characterizing and monitoring the energy transfer from the solar wind to the magnetosphere. The solar wind cou- pling to the magnetosphere and ionosphere, and the associated energy transfer can also be evaluated directly from the dayside Region-1 (R-1) field-aligned currents (FAC). Ijima and Potemra (1982) have quantified the relationship between these R-1 current densities and the interplanetary parameters.

We have deduced the FAC density from magnetic field measurements collected from 29 May at 06:00 UT, until 30 May at 12:00 UT, by the low-altitude polar orbiting CHAMP satellite (Reigber et al., 1999). During this period, the satellite crossed the northern auroral ionosphere in the early-afternoon (15:00-16:00 MLT) sector. Figure 8 shows estimates of the R-1 current obtained by integration of the FAC density over its full latitudinal extent. The R-1 current exceeds $0.7 \mathrm{~A} / \mathrm{m}$ for 12 successive passes, from 13:15 UT on 29 May until 06:10 UT on 30 May. This period encompasses the passage of the magnetic cloud. The maximum value of $3.5 \mathrm{~A} / \mathrm{m}$ is observed during the 22:20 UT pass on 29 May at the time of maximum solar wind pressure associated with the largest negative IMF $B z$. This value is more than 10 times the typical quiet time value of $0.25 \mathrm{~A} / \mathrm{m}$ (Potemra, 1994). The northward turning of the IMF is followed by a strong decrease in the R-1 current, down to $1 \mathrm{~A} / \mathrm{m}$, a value significantly larger than the pre-storm value $(0.5 \mathrm{~A} / \mathrm{m})$. This persisting R-1 current may be attributed to the persisting high solar wind pressure. Similar observations have been made by Le et al. (1998) during a period of positive $B z$ and high solar wind pressure following the January 1997 storm, where the R1 current was observed to remain at twice its pre-storm intensity. The solar wind pressure has also been shown to correlate positively with the intensity of the auroral electrojets for positive $B z$ (Shue and Kamide, 2001).

Our observations demonstrate that although the negative $B z$ is the dominant factor controlling the energy input to the magnetosphere, the large solar wind pressure also plays an important role, even during periods of positive $B z$. In their analysis of the northward IMF period following the 22-24 October 2003 magnetic cloud, Øieroset et al. (2005) observed a gradual transition to a cold and dense plasma sheet, together with reversed ion dispersion signatures in the cusp, indicative of reconnection poleward of cusp. These observations agree with a global MHD simulation ( $\mathrm{Li}$ et al., 2005), in which magnetosheath plasma entering the magnetosphere poleward of the cusp is convected to the tail. It has also been shown by Feldstein et al. (1984) that finite energization of the ring current still occurs for positive $B z$. 
Table 3. Chronology of interplanetary (ACE), magnetospheric and ionospheric events.

\begin{tabular}{lll}
\hline Day / Time UT & Event & Observed in \\
\hline $29 / 12: 25$ & Interplanetary shock - Sudden Impulse & ACE data, SYM-H \\
$29 / 13: 50$ & Substorm & AE, ASY-H \\
$29 / 15: 14$ & Substorm & AE, ASY-H \\
$29 / 16: 10$ & Pressure pulse \& Substorm & ACE data, AE, ASY-H \\
$29 / 19: 06$ & Interplanetary shock - Sudden Impulse & ACE data, AE, ASY-H \\
& Substorm & \\
$29 / 22: 50$ & Substorm & AE, ASY-H \\
$30 / 01: 50$ & $B z$ northward & ACE data \\
\hline
\end{tabular}

Both the negative IMF $B z$ and the high solar wind pressure are responsible for the equatorward motion of the R-1 current by as much as $10^{\circ}-12^{\circ}$ (Fig. 8, centre panel). During the positive $B z$ period after 02:00 UT on 30 May, a strong downward current (the northward $B z$ or NBZ current, Ijima et al., 1984) is observed poleward of the R-1 current. This NBZ current is also a manifestation of solar wind-magnetosphere coupling, due to reconnection occurring poleward of the magnetospheric cusps.

\section{Magnetosphere - ionosphere coupling}

5.1 Parameters characterizing the state of the magnetosphere - ionosphere current system

Geomagnetic indices can be used to monitor and characterize the global response of the magnetosphere-ionosphere system. They are computed from geomagnetic field variations recorded at ground-based observatories, and most of them constitute data series which are homogeneous over the four latest solar cycles. SuperDARN radars are another powerful means of monitoring the magnetospheric and ionospheric responses by mapping the plasma convection over the whole polar cap. Unfortunately, data are usually unavailable during very intense magnetic storms, due mainly to increased absorption of HF radio waves in the D region. This was indeed the case on 29 May (see Sect. 7.1). Therefore, we have chosen to describe magnetospheric and auroral activity at a global level using the PCN,AE, $D_{s t}$, SYM-H and ASY-H geomagnetic indices.

The Polar Cap (PC) magnetic index has been proposed by Troshichev et al. (1979, 1988). It is based on a statistical analysis of the relationship between the solar wind merging electric field and the magnetic disturbances observed at near-pole stations, one in each hemisphere. We only consider here the northern PC index $(P C N)$. It is representative for the magnitude of the northern trans-polar convection electric field which drives the transpolar part of the ionospheric two-cell DP2 current system. As a result, increasing $P C N$ values can be interpreted as increasing dayside merging, as indicated by the good correlation between the R-1 current and the $P C N$ index shown in Fig. 8 (bottom panel).
The auroral activity indices ( $A E, A U, A L, A 0$, classically referred to as $A E$ indices or simply $A E$ ) have been introduced by Davis and Sugiura (1966). They are at present based on the transient variations in the geomagnetic north component observed at a network of 11 observatories distributed in longitude over the auroral oval. $A E$ monitors the magnetic activity produced by enhanced ionospheric currents in the auroral zone, mostly related to the magnetosphereionosphere coupling through the field-aligned currents. It is worth noting that $A E$ stations are located at standard auroral oval latitudes. They may fail to properly capture the magnetic signature of the auroral phenomena during periods of intense geomagnetic activity, as a result of the associated equatorward motion of the auroral oval. As will be shown in the following section, this happens during some periods of the event we consider here.

The $D_{s t}$, derived on a 1-h basis, measures the variations in the geomagnetic north component at four low-latitude observatories (Sugiura, 1965; Sugiura and Kamei, 1991). It monitors the axi-symmetric part of the magnetospheric currents, including mainly the ring current, but also the magnetopause Chapman-Ferraro current. The SYM-H index is essentially the same as Sugiura's hourly $D_{s t}$ index, but with the advantage of being derived on a 1-min basis and from a different set of stations. The ASY-H index measures both the direct and the unloading response of the magnetosphere (partial ring current). In particular, the signature of substorm onsets takes the form of a sharp positive peak in ASY-H and in $A E$. In the present study, we use SYM-H (one-minute time resolution) or $D_{s t}$ (1-h time resolution), depending on the context. The time histories of the indices are displayed in the lower panels of Fig. 6 for $A E$, SYM-H and ASY-H, and in Fig. 8 for $P C N$.

\subsection{Electrodynamics of the magnetosphere-ionosphere sys- tem}

Table 3 lists the time sequence of the essential events of the most disturbed period starting with the first interplanetary shock. Several substorms occur, either isolated or triggered by the solar wind pressure pulses and inducing two small amplitude events on the SYM-H index, which decreases to -50 and $-70 \mathrm{nT}$, respectively. The second shock at 19:06 UT, 


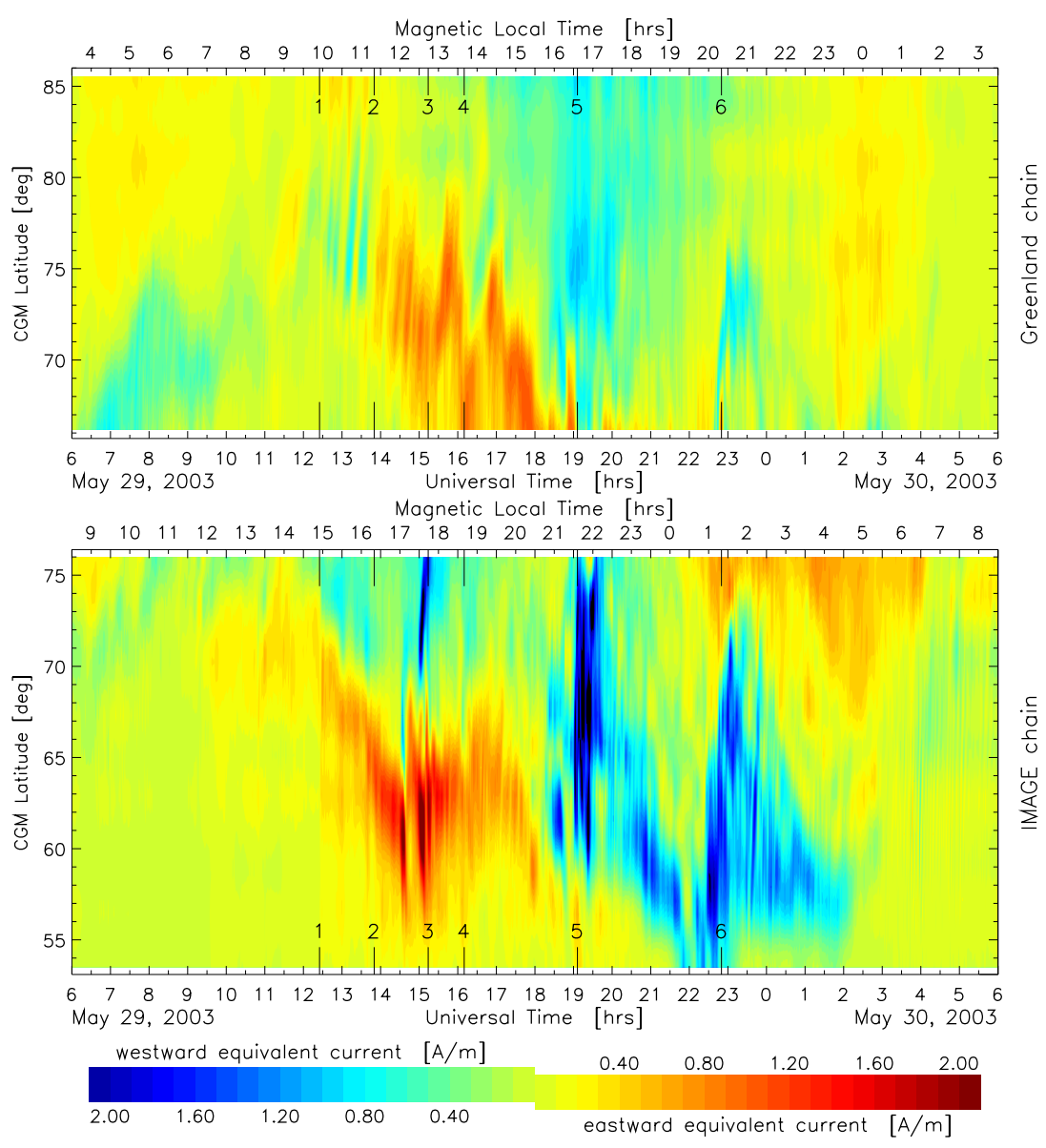

Fig. 9. East-west component of the equivalent ionospheric current derived from magnetometers measurements along the Greenland west coast (top panel) and IMAGE (bottom panel) chains, respectively. Note that the chain meridians differ by about 5 hours in magnetic local time.

which is associated with the period of largest negative $B z$ $(-32 \mathrm{nT})$, initiates the most active period, as seen by all indicators. It corresponds to the largest R-1 current and $A E$ values. The largest ASY-H values $(300 \mathrm{nT})$ are observed after 19:06 UT and 22:30 UT. The SYM-H index reaches its largest negative value of $-150 \mathrm{nT}$ with about a $3-4 \mathrm{~h}$ delay at 23:15 and 02:00 UT. After the 22:50 UT substorm, the activity decreases, with $B z$ alternating between positive and negative values before turning positive and remaining so from 01:53 UT onward.

The $A E$ and $P C N$ magnetic indices are indicative of the large-scale, high-latitude current systems, namely the auroral electrojets and the trans-polar cap Hall current, which together form the basis of the polar convection cells. We use these indices to guide our more detailed discussion of highlatitude current patterns inferred from two nearly-meridional magnetometer chains along the Greenland west coast and in Scandinavia (Fig. 9, upper and lower panels, respectively), the latter being known as IMAGE (Viljanen and Häkkinen, 1997). The east-west oriented equivalent ionospheric currents above Greenland were computed using the inversion method proposed by Popov et al. (2001) and above Scandinavia using a method of upward continuation (e.g. Mersmann et al., 1979; Untiedt and Baumjohann, 1993).

In the following we use the term "Hall current" when referring to these currents, although this is not exactly correct under all ionospheric conditions. FAC, electric field and ionospheric conductance patterns can exist in a way such that the equivalent current (the divergence-free part of the horizontal ionospheric current) differs substantially from the Hall current (the cross-electric field current). This case occurs specifically at electric conductance gradients, e.g., at the day/night terminator and at the edge of ionospheric plasma structures (see Sects. 2.4.2 and 2.4.3 in Untiedt and Baumjohann, 1993, for sample cases). At worst, both direction and intensity of the equivalent ionospheric current may have little in common with the true ionospheric current. Equivalent current patterns can therefore only be interpreted in a meaningful way if combined with other sources of information, e.g., magnetic indices (most of which are non-local measures) or current distributions derived simultaneously from different locations and from satellites. In spite of their limitations the large 
spatial coverage and high time resolution of magnetometer arrays make the equivalent currents a useful tool for studying ionospheric variations.

Both the $P C N$ (Fig. 8) and the $A E$ (Fig. 6) indices are rather small during the morning hours of 29 May 2003. Right after 12:25 UT, upon the arrival of the first shock, they increase modestly but sharply, indicating an enhancement of the auroral electrojet intensity and the trans-polar cap current. The rise is particularly clear in the Scandinavian sector (at that time located in the early afternoon sector) where it is accompanied by an equatorward motion of the equivalent current system which continues for several hours (Fig. 9). In contrast, it is noticed in the Greenland sector (located in the late morning) as only a short-lived spike followed by several small poleward propagating perturbations up to about 15:00 UT. In accordance with the increasing IMF $B y$ component after 14:00 UT an eastward directed DPY current system (Wilhjelm et al., 1978) develops in the noon sector above Greenland. The IMAGE chain witnesses the intensification and equatorward expansion of the eastward electrojet in the afternoon and evening sectors. Three peaks in the $A E$ index, shortly after 13:30 UT, just before 15:00 UT and right after 16:00 UT, are more or less clearly seen as enhancements of the current above Scandinavia but not in the Greenland sector. This is most likely due to the fact that Scandinavia is favourably placed under the eastward electrojet while Greenland is in the noon sector where the east-west current is weak (except for the DPY current). The 15:00 UT peak coincides with a rise of the $P C N$ index, indicating that the Hall current intensity of the polar convection cells has increased.

A more pronounced increase of both the $P C N$ and $A E$ indices, however, appears at 19:00 UT and is most likely related to the arrival of the most prominent solar wind shock which was discussed above. The eastward electrojet is driven further equatorward, and both Scandinavia and Greenland are exposed to relatively strong westward currents covering a wide range of latitudes. Greenland is located in the dusk and IMAGE in the pre-midnight sector. This observation suggests that the polar cap has expanded significantly, and the current observed above Greenland is part of the trans-polar cap Hall current while the very intense westward current over Scandinavia maps to the edge of the morning convection cell. This indicates that the shock caused a substantial change in the polar cap convection.

During the following hours the high-latitude current intensity diminishes while the westward current over Scandinavia is observed to move equatorward. Around 22:30 UT, upon the arrival of the last pressure pulse, the $P C N$ and $A E$ indices start to grow to high values and the westward electrojet intensifies again, accompanied by a poleward expansion (i.e. oval widening), first in the Scandinavian sector and shortly after above Greenland. The $P C N$ and $A E$ reach their peaks at about 23:00 UT (coinciding with the peak current densities measured by the two chains) and then decrease significantly to only moderate values. We can assume that both chains are located under the morning cell and observe that the convection intensifies greatly but does not move equatorward, i.e. the expansion of the polar cap is only moderate. Only from about 23:30 UT onward is a weakening of the currents and a concentration of the westward current at lower latitudes $\left(55^{\circ}-60^{\circ} \mathrm{CGM}\right)$ observed while the higher latitudes (above $70^{\circ} \mathrm{CGM}$ ) are dominated by a moderately strong eastward current. It does not last long and is not particularly intense, probably because of reduced magnetic field merging between the interplanetary space and the magnetosphere (IMF $B z$ has become strongly positive). After 04:00 UT the storm seems to cease, and the polar cap current and electrojet intensity (as manifested by the $P C N$ and $A E$ indices, respectively) become very low. Both the Greenland and the IMAGE chain confirm this observation.

Finally, it is worth noting that all indicators agree to evidence a very large expansion of the auroral oval to lower latitudes. Quantitative indications come from the motion of the auroral electrojets and from the R-1 currents (see Sect. 4.2). Both suggest a $10^{\circ}$ equatorward expansion of the auroral zone between 10:00 and 24:00 UT which proceeds in steps, with intermittent relaxation and expansion. At least three major expansion periods are observed, the first from 12:30 UT to about 19:00 UT, the second from about 20:00 UT to 22:30 UT and the third from 23:30 UT to about 02:00 UT. The observation of aurora until 01:50 UT on 30 May at medium latitudes provides another observational evidence of such an expansion.

Figure 10 displays the electron density in the E-region and the electric field measured by EISCAT at Troms $\varnothing$ (66.6 magnetic latitude) on 29 May between 12:00 and 24:00 UT. During that period, EISCAT moves across the nightside of the Earth from 17:00 to 05:00 MLT in the morning, crossing the Harang discontinuity around 18:00 UT, as indicated by the reversal of the meridional component of the electric field. The electron density remains high, particularly during the main phase of the storm after 19:00 UT, due to electron precipitation. When located under the eastward electrojet, EISCAT observes large northward electric fields with values up to $100 \mathrm{mV} / \mathrm{m}$ (equivalent to a westward plasma convection velocity of $2 \mathrm{~km} / \mathrm{s}$ ), which are well correlated with the current intensifications at the same latitude deduced from IMAGE (Fig. 8). Large peaks in electron density indicate keV electron precipitation related to the substorm activity and auroral intensifications or possibly to the events of magnetospheric compression. Periods of large eastward electric field (northward convection velocity) occur which indicate either the propagation of convection vortices or northward motions of auroral arcs related to substorms. They are systematically associated with sharp enhancements in the E-region electron density, probably due to bursts of electron precipitation.

\section{Thermosphere - ionosphere response}

The reaction of the coupled ionosphere-thermosphere system to the magnetospheric energy input proceeds in several ways. Joule heating, due to the increased convection electric field and horizontal currents, is the primary auroral energy input 


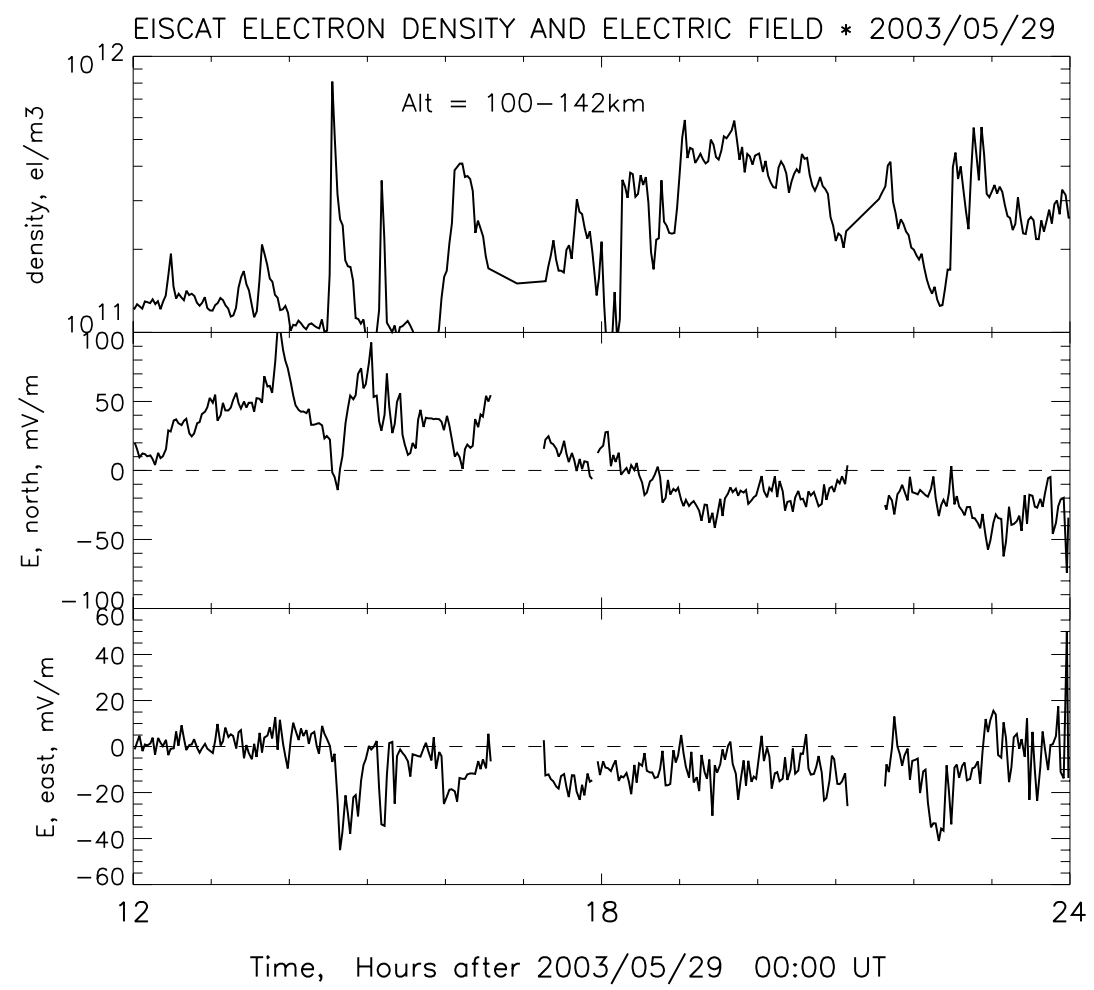

Fig. 10. Electron density in the ionospheric E-region and electric field on 29 May 2003 inferred from EISCAT measurements.

to the thermosphere besides particle precipitation. Knipp et al. (2005) have quantified the contribution of auroral energy to the total global heating budget of the upper atmosphere. While it usually amounts to about $17 \%$, it may occasionally rise to $50 \%$ during intense geomagnetic storms, leading to major perturbations of the thermosphere-ionosphere on a global scale. The role of solar wind pressure variations in heating the auroral ionosphere has also been discussed recently on the basis of MHD-simulations by Palmroth et al. (2004).

Indeed, at the latitude of the expanded auroral oval, Joule and auroral particle heating drive a divergent wind that forces upwelling of the neutral gas to a higher altitude resulting in neutral composition disturbance zones. Neutral winds, resulting from both the background daily circulation and perturbations induced by ion drag, transport auroral disturbances away from their source regions towards middle and low latitudes (e.g. Burns et al., 1995; Fuller-Rowell et al., 1997). Such disturbances increase the proportion of molecular species in the upper atmosphere and this enhances ionisation loss by dissociative recombination, resulting in a decrease of ionization, the so-called negative storm phase (e.g. Prölss et al., 1991; Förster and Jakowski, 2000). At auroral latitudes, the response of the ionosphere is, however, more complex: particle precipitations result in local increases of electron density, mainly at E-region altitudes (e.g. in Fig. 10) while convection flows transport F-region ionisation far from its source region. After this initial period, a decrease in elec- tron densities in response to changes in the atmospheric composition may be observed.

The increase of the thermospheric meridional circulation at auroral latitudes and the resulting density perturbations at middle latitudes have been observed and are presented in Sect. 6.1, while the more complex ionospheric signature at latitudes above $50^{\circ}$ are investigated in Sect. 6.2.

\subsection{Thermospheric wind and density}

EISCAT measurements have been used to derive the meridional component of the thermospheric neutral wind from 2731 May at 250-km altitude (Fig. 11). Assuming no significant vertical wind, the meridional wind component is derived from ion velocity measurements along the magnetic field line. This method has been extensively used to describe the thermospheric meridional wind at middle and high latitude during quiet magnetic periods (i.e. Buonsanto et al., 1999; Witasse et al., 1998). During disturbed periods at auroral latitudes, vertical winds develop mainly at small spatial and temporal scales. The above method, however, allows one to derive reliable estimates of the large-scale daily variation of the meridional wind. We have used here a 2-h running average of the 1-min EISCAT data. As compared to the quiet time model (Witasse et al., 1998), Fig. 11 shows that the thermosphere circulation is already disturbed on 28 May in response to the PCIR observed at ACE (see Sect. 3 and Fig. 5). During daytime, the poleward wind is enhanced, while during nighttime an equatorward increase is observed 


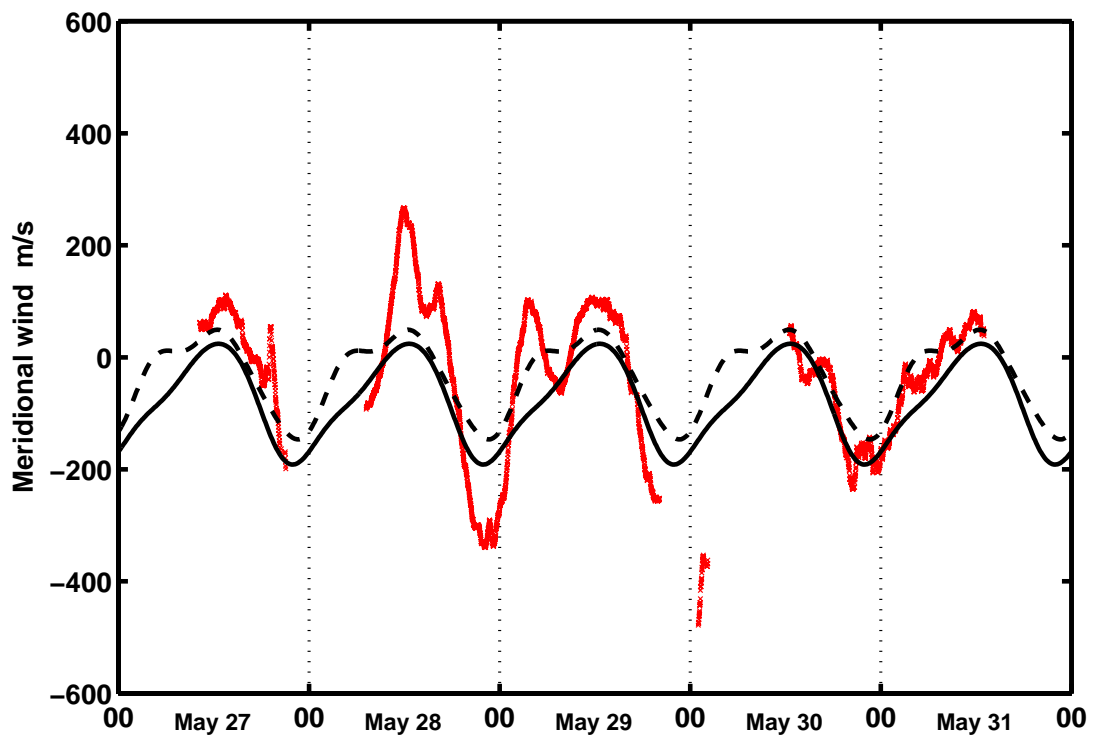

Fig. 11. Meridional wind at 250-km altitude deduced from EISCAT observations from 27-31 May (red) in comparison with the quiet-time model of Witasse et al. (1998) for summer conditions. High (low) solar activity is plotted as a dashed (solid) black line.

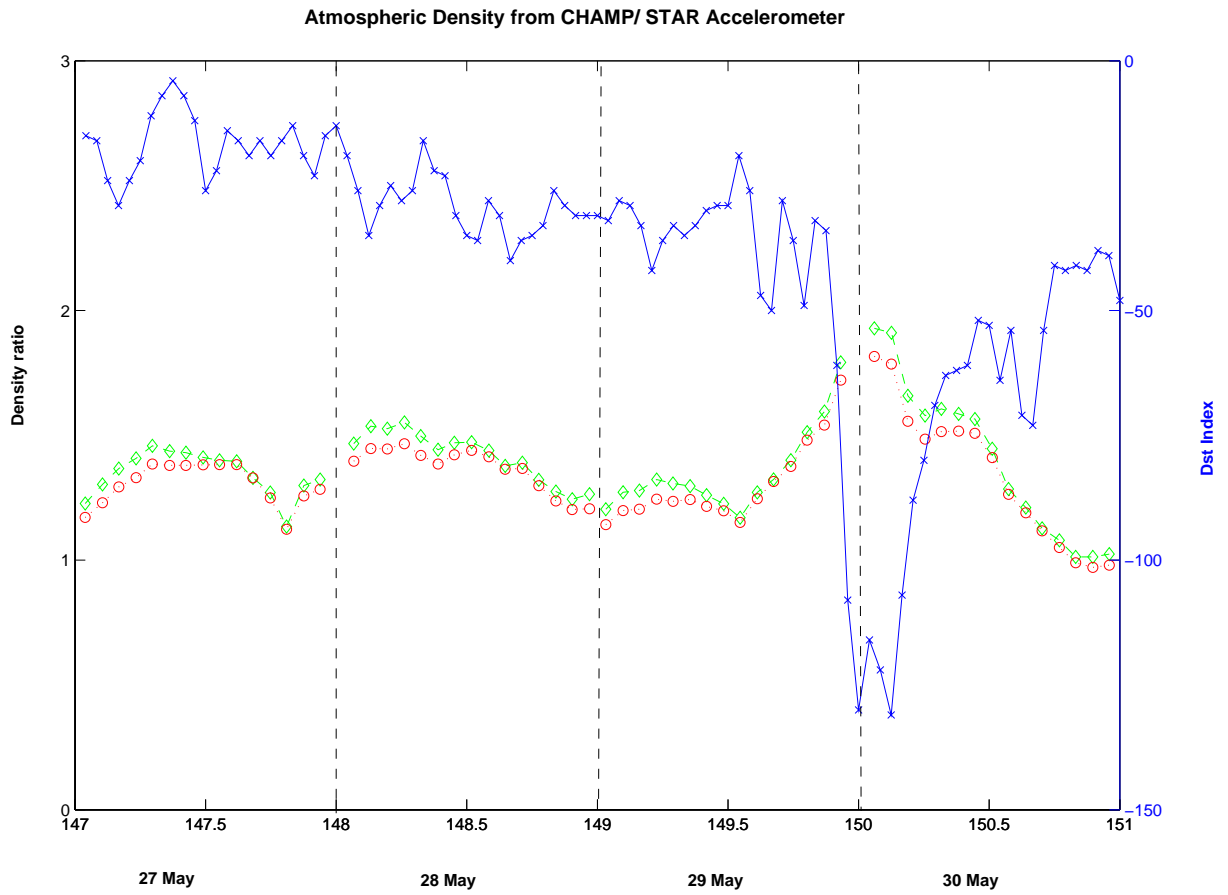

Fig. 12. Thermospheric density ratio deduced from the STAR accelerometer on board the CHAMP satellite. Red (green) symbols correspond to a normalisation with the MSIS-90 (NRLMSISE-00) models run for quiet magnetic conditions. The blue line shows the $D_{s t}$ magnetic index.

that maximizes during the 29-30 May night. The following night, the auroral thermospheric circulation has returned to normal, i.e. an equatorward wind at midnight with its amplitude twice as small.

The total thermosphere density is retrieved from STAR accelerometer measurements on board the CHAMP satellite at an altitude around $400 \mathrm{~km}$. The method for obtaining the neutral density from the tangential acceleration is described in Bruinsma et al. (2004). Upper atmosphere winds are not taken into account while retrieving the density. Resulting errors on densities maximize at $5 \%$ per $100 \mathrm{~m} / \mathrm{s}$ wind amplitude. Because the winds increase significantly at auroral latitudes during storms, the high latitude parts of the orbits are not used. The response of the thermosphere density is described in terms of its relative variations, normalized using the semiempirical model MSIS-90 (Hedin, 1991) and the more recent one, NRLMSISE-00 (Picone et al., 2002). Both depend on the solar radio flux (given by the F10.7 index) and 

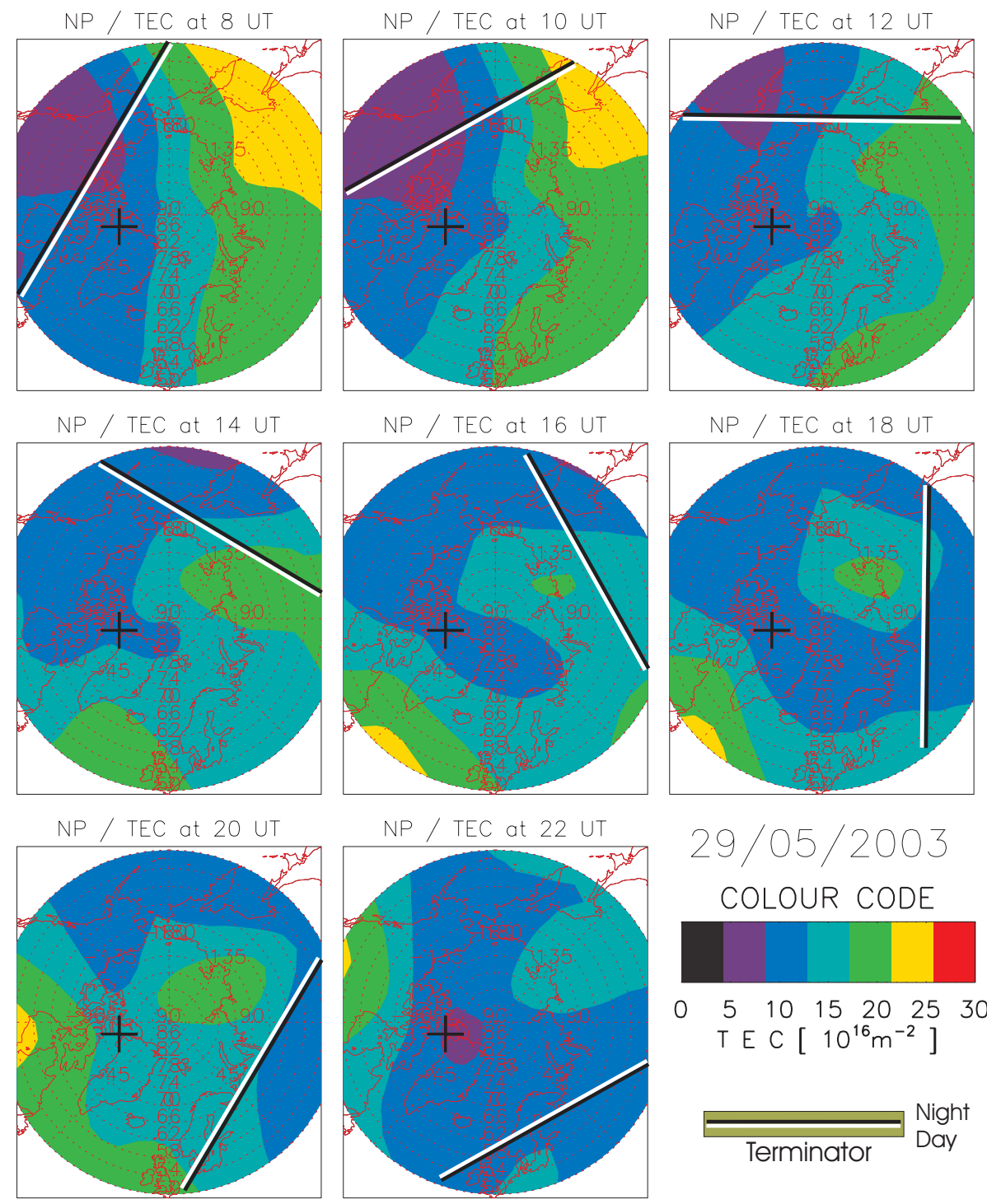

(a)

Fig. 13. (a) Two-hourly polar TEC maps showing TEC down to $50^{\circ} \mathrm{N}$ latitude on 29 May 2003.

the magnetic activity (given by $A p$ indices), but quiet geomagnetic conditions (daily $A p$ of 4 ) have been used here. These relative densities have been averaged over latitudes from $-50^{\circ}$ to $+50^{\circ}$ for every daytime orbit, from $27-30$ May. Figure 12 shows the variation with time of the so-obtained daytime average relative density. It indicates that upon the arrival of the first interplanetary shock which marks the begin of the high activity period (12:30 UT on 29 May) the mid- and low-latitude density perturbation starts to grow and the density ratio increases from its $1.0-1.3$ pre-storm numbers to a peak of nearly 2.0 which is reached in the morning of 30 May, at the same time when $D_{s t}$ reaches a minimum.

\subsection{Total electron content (TEC)}

The integral of the electron density (called total electron content or TEC) along the ray path, from a GNSS satellite to a ground-based receiver, can be computed from dual- frequency GPS measurements using the dispersive properties of the ionospheric plasma. After calibration (Sardón et al., 1994) the measured slant TEC is mapped to the vertical by using a single layer approximation at an altitude of $400 \mathrm{~km}$ for the ionosphere. The computed TEC data are combined with the empirical TEC models, in order to generate TEC maps, (Jakowski, 1996) as shown in Figs. 13a-b.

Early on 29 May at 08:00 UT, the geomagnetic activity is low and the TEC exhibits a normal day-night structure (Fig. 13). The ionospheric convection increases afterwards, starting from the late afternoon/evening sector and moving the plasma towards the nightside across the polar cap. The strongest convection pattern develops around 20:00 UT, consistent with the $P C N$ index increase shown on Fig. 8. This strong ionization enhancement is followed by a decrease in ionization. This negative storm phase, which starts in the region of the geomagnetic pole around 22:00 UT, subsequently extends over the Northern Hemisphere and lasts during the 

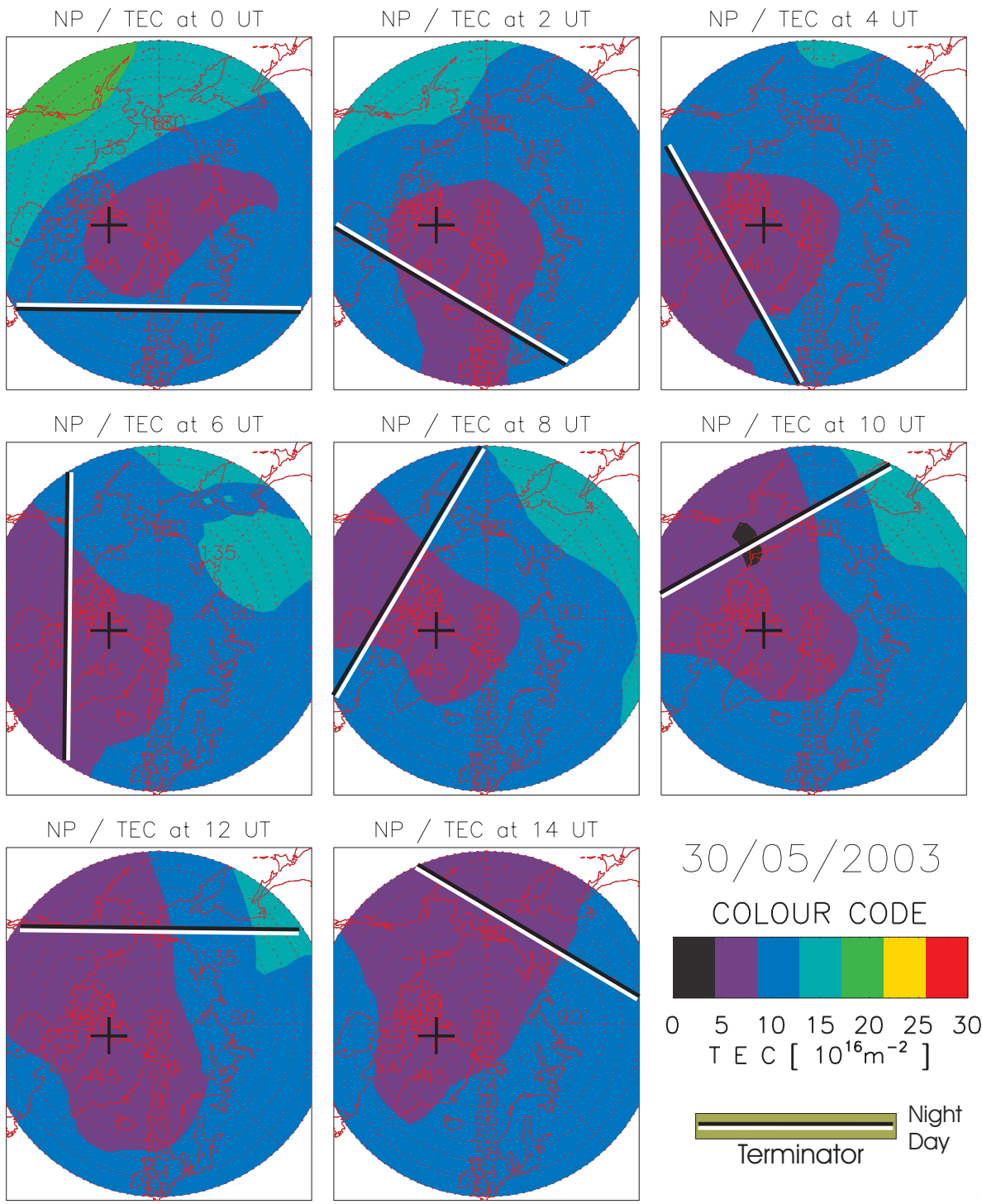

(b)

Fig. 13. (b) Same on 30 May 2003.

full day on 30 May (Fig. 13b). It is rather surprising that the beginning of the negative phase does not occur in the auroral region, where the first impact of upwelling from the lower atmosphere is expected to appear. It might be that some transport effects also contribute in addition to thermospheric heating, but more knowledge of the local ionosphere would be needed in order to answer this question.

The temporal TEC variation at three selected latitudes along the $75^{\circ} \mathrm{W}$ meridian (Fig. 14) shows a nearly simultaneous and noticeable jump in the TEC by about $5 \times 10^{16} \mathrm{~m}^{-2}$ at 20:00 UT, just after the start of the most active phase of the storm. A second peak occurs at 23:00 UT at the auroral latitudes $70^{\circ}$ and $60^{\circ}$, associated with the second most active phase of the storm (see, for instance, the $A E$ index, Fig. 6). During this period, the density variations are driven by precipitation and plasma transport. Keeping in mind the EISCAT observations (Sect. 5.2), this suggests that the main contribution to the TEC is provided by the E-region. Im- mediately afterwards, the onset of the negative storm phase due to atmospheric composition changes is observed. At all latitudes, a sharp TEC increase is observed just after 06:00 UT, which may be attributed to the passage of the meridian in the midnight MLT sector where plasma may be transported from the dayside. The negative phase dominates at all latitudes after 08:00 UT on 30 May.

\section{Space weather impacts}

Numerous adverse effects result from the perturbations of the magnetosphere-ionosphere-atmosphere system. A few of them are discussed below. High energy auroral precipitation is the source of low altitude ionisation, leading to HF absorption (Sect. 7.1), and plasma instabilities, leading to scintillations (Sect. 7.2). Increased atmospheric density results in satellite orbit perturbations (Sect. 7.3). 

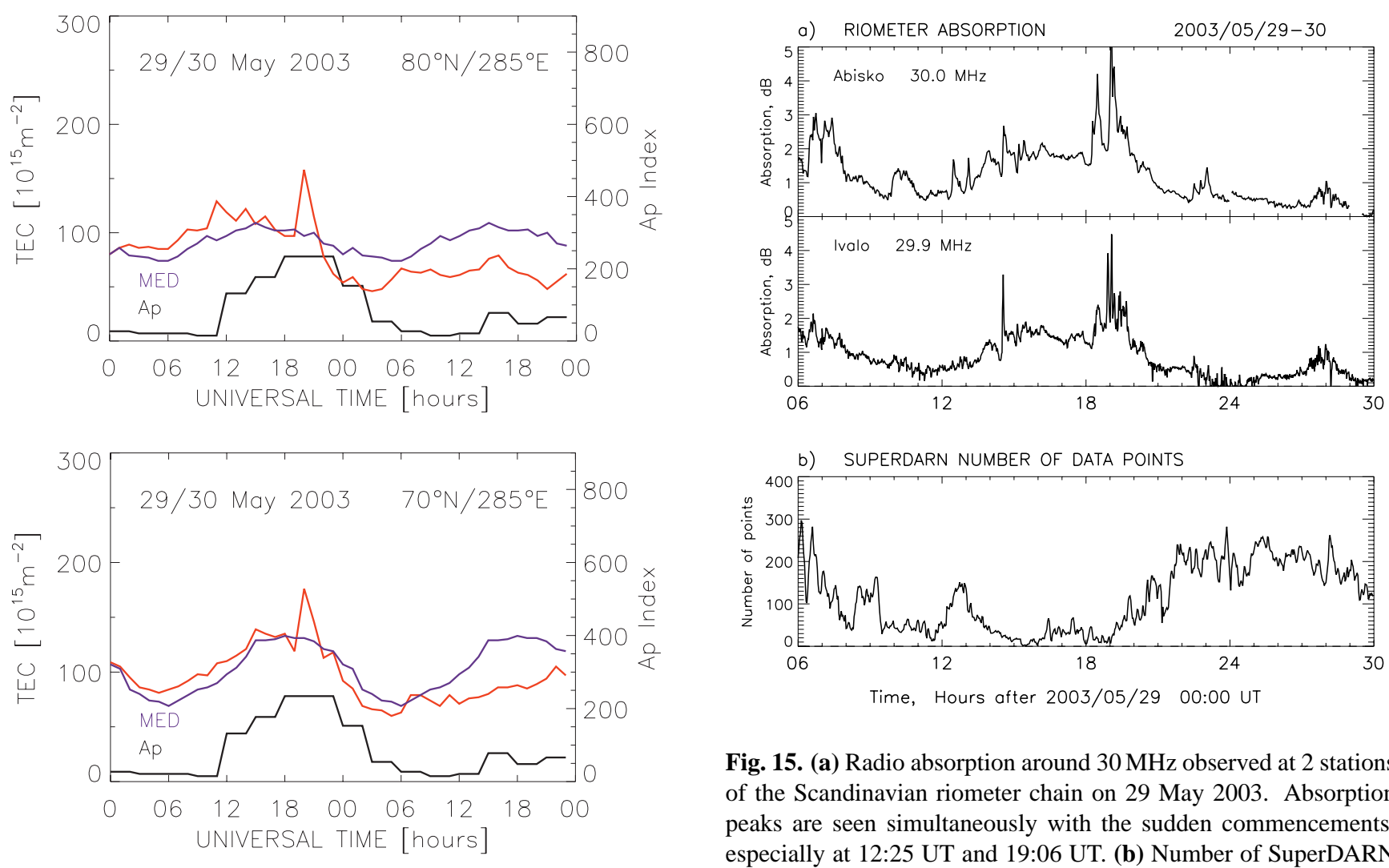

Fig. 15. (a) Radio absorption around $30 \mathrm{MHz}$ observed at 2 stations of the Scandinavian riometer chain on 29 May 2003. Absorption peaks are seen simultaneously with the sudden commencements, especially at 12:25 UT and 19:06 UT. (b) Number of SuperDARN data points available from the Northern Hemisphere radar network. As a consequence of the radio blackout, it remains below 300 for the whole period and is close to zero from 09:00 UT until 18:00 UT (around 600 is typical under average conditions).

lar proton event started at 23:35 UT on 28 May and reached its maximum at 15:30 UT on 29 May. It produced an increase in the background absorption. In addition, peaks in absorption occur simultaneously with the sudden impulses. At 12:25 UT a peak is seen in the Abisko data but not at Ivalo, located at the same latitude, probably because of its later local time. At 19:06 UT peaks are present at both stations (larger at Abisko). The peaks present at both stations at 14:30 UT (larger at Ivalo) is not related to any of the events

Fig. 14. Diurnal variation of TEC (red) for the latitudes 80,70 and $60^{\circ} \mathrm{N}$ along the $75^{\circ} \mathrm{W}$ meridian on 29-30 May 2003. The monthly median TEC values (blue) are shown for comparison, together with the 3-hourly $A P$ magnetic index (black).

\subsection{HF absorption}

D-region electron density is mostly controlled by hard Xrays, Lyman- $\alpha$ ionization of NO and, during solar events, electron precipitations at energies up to a few $100 \mathrm{KeV}$. Increased D-region plasma density leads to increased absorption of the cosmic radio noise in the $20-50 \mathrm{MHz}$ range as measured by riometers. Figure 15 a shows the data from 2 stations of the Finnish chain (e.g. Ranta et al., 1981) on 2930 May. The effects of hard X-rays emitted by the flares on 27-28 May, and coincident with them, are not shown. A solisted in Table 3 but corresponds to a peak in EISCAT electron density data in Fig. 10. All of these peaks in absorption are probably associated with short-lived increases in Dregion ionization, due to bursts of relativistic electron precipitations generated by acceleration processes on auroral field lines.

The increase in radio absorption is at the origin of a radio blackout and has a strong impact on HF radar observations. Figure $15 \mathrm{~b}$ shows the total number of data points available from the northern SuperDARN chain for deriving polar cap potential maps during the $24 \mathrm{~h}$, starting on 29 May at 06:00 UT. This number remains always below 300 and is close to zero from 09:00 UT to 18:00 UT, as compared to an average number of at least 600 during usual conditions. This explains why it becomes impossible to derive representative potential maps and cross-polar potential values. 
(a) 29/05/03 06:00-12:00

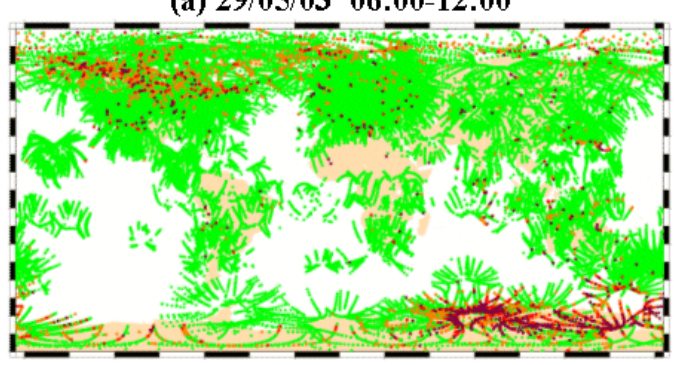

(c) 29/05/03 18:00-24:00

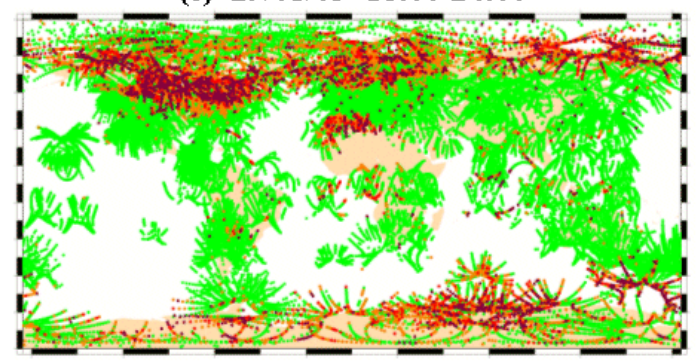

(b) 29/05/03 12:00-18:00

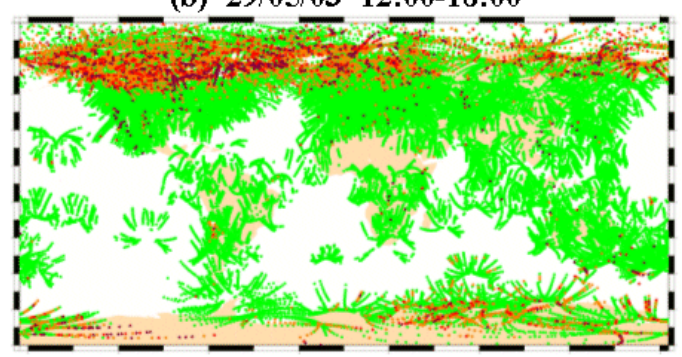

(d) 30/05/03 06:00-12:00

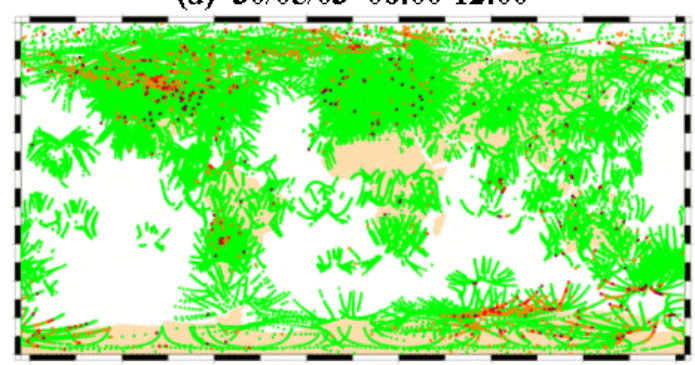

Fig. 16. Global maps of scintillation level estimated from high frequency GPS radio signal phase fluctuations on 29 May 2003 . Each point corresponds to a satellite-ground receiver link mapped to the sub-ionospheric point. Scale level: $0-0.25$ for low, $0.25-0.5$ for moderate, $0.5-0.75$ for strong, $>0.75$ for severe. The successive maps show the equatorward expansion of the auroral zone and the increase in scintillation level associated with the storm.

While the radar echoes disappear at a global scale due to increased absorption, it is also well known that the arrival of a pressure perturbation at the magnetosphere leads locally to the creation of field-aligned currents and to the formation of characteristic vortex-like structures in the ionosphere (Araki, 1994). Radar echoes, produced by unstable density gradients, resulting from increased precipitation (e.g. Zhou and Tsurutani, 1999), are locally triggered by a pressure pulse (Ballatore et al., 2001; Coco et al., 2005). This phenomenon is at the origin of the two increases in data point number seen in Fig. 15, one from 12:00 UT until 14:00 UT and the other one after 19:00 UT. Both of them begin at the time of the sudden commencements. Looking at the detailed SuperDARN data, the echoes are returned from localized spots, slightly north of Troms $\varnothing$ at 12:00 UT and over Alaska around 19:00 UT.

\subsection{Ionospheric scintillations}

The high-latitude ionospheric plasma is structured at various scales under the effect of plasma instabilities acting on electron density gradients related to electron precipitations. Scintillations are the fluctuations observed on radio signals as they are scattered in the forward direction by the F-region plasma fluctuations within the hundred of meters wavelength. They are a major source of disturbance for ground-satellites radio links. In the scope of the ESA Space Weather Pilot Project, CLS (Collecte Localisation Satellites) has developed a prototype service to monitor ionospheric scintillations at a global scale in near real time. An empirical index is derived from the analysis of GPS signal perturbations provided by the IGS worldwide permanent network of about 300 receivers. It is derived from the high-frequency fluctuation of the GPS dual frequency phase difference that only contains the effect of ionospheric refraction on the signals. This index is scaled by comparison with scintillation monitor records from Douala (Cameroon).

The algorithms have been applied to the 29-30 May period for 6-h time intervals and the result is presented in Fig. 16. Each point on the map corresponds to an individual measurement with a 30-s resolution. Starting from a relatively quiet scintillation level before 12:00 UT on 29 May (Fig. 16a), the beginning of the storm at 12:25 UT triggers both an increase in the scintillation level and an equatorward expansion of the scintillation region identified to the auroral zone (Fig. 16b). These effects maximize during the 18:00-24:00 UT period (Fig. 16c) already identified as the period of maximum expansion of the auroral zone from the magnetometer and auroral data. The ionosphere returns slowly to a quiet level at the end of the storm (Fig. 16d). These maps have to be interpreted with care. For example, the number of available ground stations influences their appearance, as is the case over North America. In this region, the scintillations look more intense only because the number of points is larger. Similarly, a region of high scintillation level appears over the Mediterranean Sea between 18:00 UT and 24:00 UT. It is associated with signals received by at least 3 stations in Spain and 2 stations in Italy, and is probably due to spurious effects. 
Kiruna $\left(68^{\circ} \mathrm{N}, 21^{\circ} \mathrm{E}\right)$

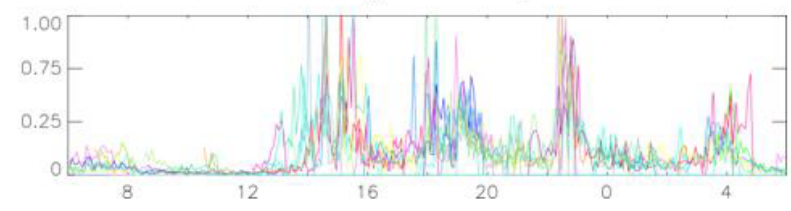

Churchill $\left(59^{\circ} \mathrm{N}, 266^{\circ} \mathrm{E}\right)$

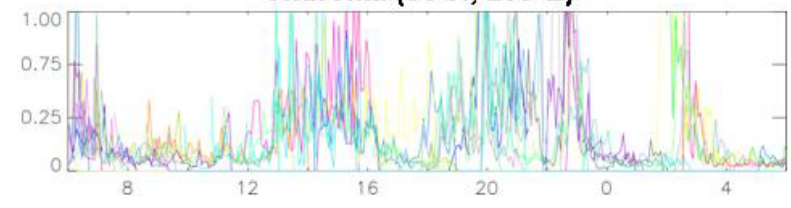

Fairbanks $\left(65^{\circ} \mathrm{N}, 212^{\circ} \mathrm{E}\right)$

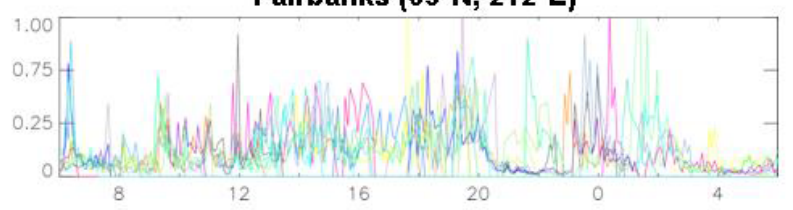

Metsahovi $\left(60^{\circ} \mathrm{N}, 2^{\circ} \mathrm{E}\right)$

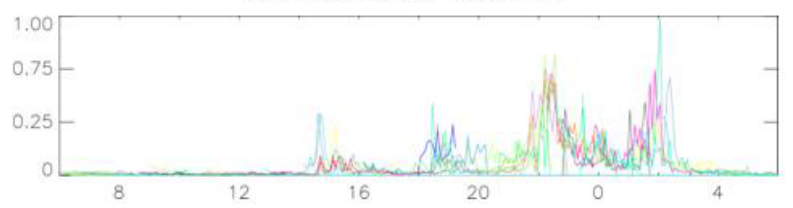

Fig. 17. Time variation of the scintillation index derived from 30-s samples at three high-latitude stations and one sub-auroral station from 29 May at 06:00 UT to 30 May at 06:00 UT. Different colours correspond to different GPS satellites. The variations in scintillation level follow the variations in the storm intensity, as shown by the magnetic indices, especially at Kiruna. Also note the delay from the auroral zone to lower latitudes due to propagation of storm-induced perturbations.

Nevertheless, its origin is not yet understood and further investigation is needed.

The time variations of the scintillations index have been plotted at three auroral stations located at Kiruna, Churchill and Fairbanks (respective magnetic latitudes $65^{\circ} \mathrm{N}, 69^{\circ} \mathrm{N}$ and $51^{\circ} \mathrm{N}$ ) and one sub-auroral location (Metsahovi, magnetic latitude $57^{\circ} \mathrm{N}$ ), for a 24-h interval starting on 29 May at 06:00 UT (Fig. 17). Each colour corresponds to one GPS satellite. During quiet periods, the scintillation level is controlled by the motion of the station into and out of the auroral zone. The main effects of the storm are the enlargement of the auroral oval through the increased convection electric field and solar wind pressure and the enhancement of the ionosperic scintillation level through intensified particle precipitation and increasingly effective plasma instabilities. The relation with the storm intensity is particularly clear in the Kiruna data, if one considers the global envelope of all the individual signals. Its variations are quite similar to the variations of the indices described previously, especially to those of the $A E$ index (Fig. 6, centre panel). The start of the storm is also very clear at Churchill and later variations of the scintillation index are broadly similar to those observed at Kiruna. This is no longer true at Fairbanks, where the storm started during the night. The difference between UT and LT is such that specific signatures of the storm are difficult to be isolated apart from a general increase in scintillation level. In the European longitude sector, the peaks in scintillation index are also clearly present at sub-auroral latitudes, as seen in Metsahovi, Finland. Compared to the Kiruna observations, their level is weaker and their appearance is delayed, as expected from the propagation of storm-induced perturbations from the auroral zone to lower latitudes. At 05:00 UT on 30 May, the ionosphere has returned quiet everywhere.

\subsection{Satellite drag}

As described in Sects. 6 and 6.1, geomagnetic storms result in heating and upwelling of the thermosphere, which means an increase in the atmospheric density at a given altitude and therefore an increase in the drag force exerted on Low Earth Orbit (LEO) satellites. Because empirical thermosphere models fail to reproduce correctly the magnitude of the perturbation (e.g. Emery et al., 1999; Lathuillère and Menvielle, 2004), the impact on the positioning is evidenced on the estimated drag coefficients in the orbit restitution process and on the orbit position error in orbit prediction.

The SPOT-2, SPOT-4, SPOT-5 and ENVISAT satellites have an on-board DORIS range measurement instrument whose aim is the precise satellite orbit determination (Tavernier et al., 2003). Everyday, operational 24-h precise orbits are calculated by the French Space Agency using a minimization scheme of the error between calculated and measured satellite-ground station radial velocity measurements. These orbit restitutions need precise acceleration models, as DORIS satellites orbit at an altitude around $800 \mathrm{~km}$, where the drag effects cannot be neglected due to the important cross-sectional surface of the platforms. The mathematical model of the orbit trajectory uses, for drag estimation, the DTM94 empirical neutral model (Barlier et al., 1978; Berger et al., 1998). It directly depends on physical parameters, and in particular, the F10.7 solar flux and the $K p$ geomagnetic indices. Minimization is obtained by applying different coefficients, among them the drag coefficient which has to be applied to the density model, and which is estimated every $6 \mathrm{~h}$.

The top panel of Fig. 18 displays the estimations of the air drag coefficient between 27 May and 1 June. The value of this coefficient would be 1.0 if the model was perfect. During most of the period, the estimations present a small variation between 0.7 and 1.3. During the 29 May storm, extreme values ranging from 0.4 to 2.2 are obtained, indicating the inadequacy of the empirical model. The bottom panel of Fig. 18 shows the differences in the along-track satellite position between the 1-day extrapolated and the 1-day adjusted orbits. On 29 May this difference reaches about $60 \mathrm{~m}$ on SPOT 5 and ENVISAT, compared to the usual mean values of the order of $10 \mathrm{~m}$. 

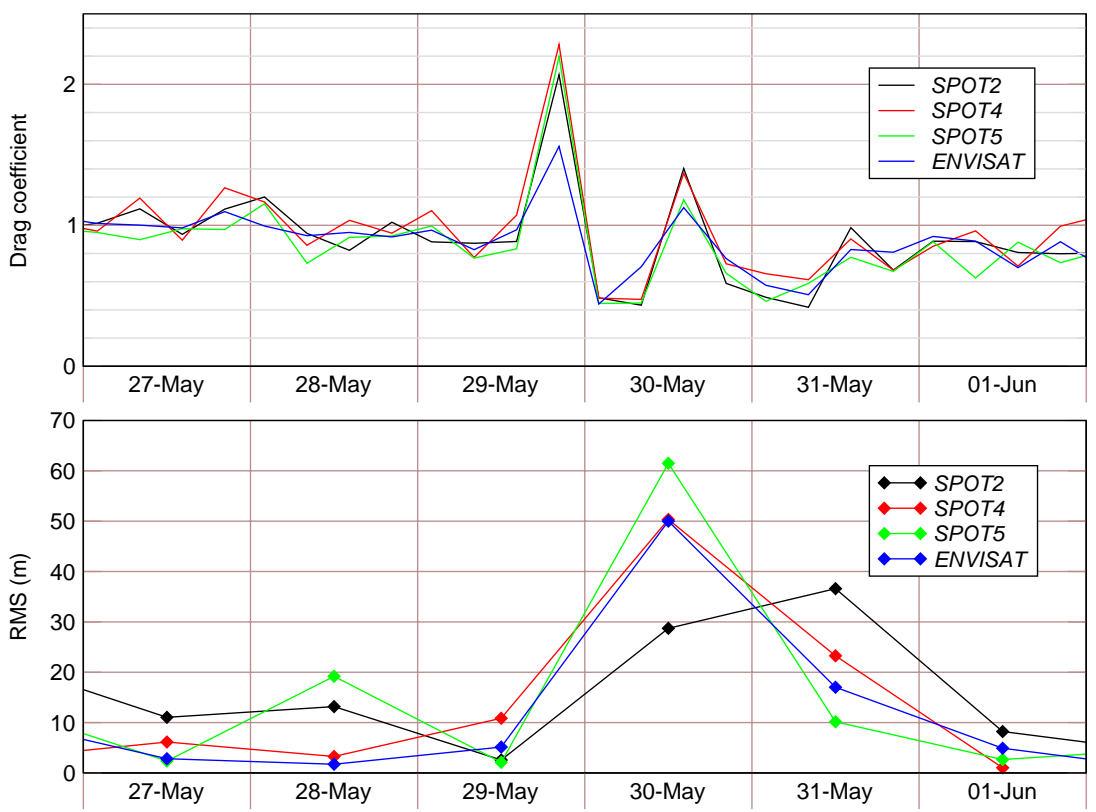

Fig. 18. Top panel: variation of the 6-h air drag coefficient estimated from data taken by the DORIS instrument flown on the ENVISAT and SPOT satellites using the DTM model. In the vicinity of the storm, the drag parameters are perturbed and their values range between 0.5 and 2.2 compared to the nominal value of 1 . Bottom panel: along-track mean position differences using 1-day extrapolated and 1-day adjusted orbits.

Table 4. May and October 2003 geospace storm main parameters.

\begin{tabular}{lcccc}
\hline Storms /2003 & May 29 & October 29 & October 31 & November 20 \\
\hline Storm intensity: & & & & \\
$\quad$ Minimum Dst (nT) & -130 & -363 & -401 & -472 \\
Source Flare Intensity & X3.6 & X17.2 & X11 & M3.2 \\
Magnetic cloud at ACE & & & & \\
$\quad|\mathrm{B}|(\mathrm{nT})$ observed & 35 & 50 & 40 & 56 \\
$\quad|\mathrm{~B}|(\mathrm{nT})$-Gonzalez et & 34 & 93 & 69 & 33 \\
al. & & & & \\
Initial CME velocity (km/s) & 1370 & 1785 & 1948 & 1660 \\
ACE SW velocity (km/s) & 750 & 2000 & 1500 & 730 \\
Estimated delay (hours) & 36 & 19 & 19 & 46 \\
Maximum AE (nT) & 2500 & 3500 & 3000 & 2500 \\
Maximum Kp / am (nT) & $9 . / 388$ & $90 / 551$ & $99_{0} / 592$ & $9_{0} / 499$ \\
\hline
\end{tabular}

\section{Discussion and conclusion}

One of the objectives of a comprehensive analysis of solarterrestrial disturbances during specific events is to determine, from one event to the other, the most pertinent factors which drive the various responses to the solar energy inputs. We have therefore chosen to compare the 29 May magnetic storm with the three major storms of the strongly disturbed October-November 2003 period (the Halloween storms of 29-31 October and the 20 November storm, Gopalswamy et al., 2005a and reference therein). Table 4 shows the main parameters of these events. When measured by the $D_{s t}$ magnetic index, the May storm appears less intense than the October-November storms. According to the classification of Gonzalez et al. (1994), the 29 May storm belongs to the "intense storm" category (minimum $D_{s t}=-131 \mathrm{nT}$ ) while the Halloween storm is a more severe one and falls into the superstorm category (minimum $D_{s t}=-401 \mathrm{nT}$ ). It is now well known (Gosling, 1993) that the central role in the chain of events leading to major geospace disturbances is attributed to CMEs through the association of their strongly southward magnetic field with the increased solar wind pressure. As already observed (Gosling, 1993) the flare intensity (as defined by the X-ray flux observed by GOES) does not correlate to the storm intensity (as defined by the $D_{s t}$ ). Although the 20 November storm is the largest one of solar cycle 23, its source CME is associated with an M-class flare while the 29 May storm follows a stronger X-class flare. More surprisingly, the halo CME generated by the flare of 4 November, estimated to have reached a maximum between $\mathrm{X} 28$ and X45 (Woods et al., 2004; Thomson et al., 2004; Brodrick et al., 2005), did not create any significant magnetospheric effect. An important characteristic of the October storms is that they were triggered by ultra fast CMEs which resulted 
in the largest solar wind velocity ever measured at $1 \mathrm{AU}$ and propagation delays shorter than one day.

Based on a statistical analysis of well-documented magnetic clouds, Gonzalez et al. (1998) have established the relationship $B_{\text {peak }}(\mathrm{nT})=0.047 \times V_{\text {peak }}(\mathrm{km} / \mathrm{s})-1.1$ between the field intensity and the solar wind velocity at $1 \mathrm{AU}$. Table 4 shows the observed and calculated peak magnetic fields at $1 \mathrm{AU}$ for the October-November storms. The comparison shows that the above relation is well fulfilled by the 29 May storm, thus making it "normal" from this point of view. In contrast, the 29 and 31 October storms are relatively undermagnetised while the 20 November storm is relatively overmagnetised. The much larger intensity of the two October storms, as compared to the May storm, can thus be attributed to several factors, namely the significantly larger absolute magnetic field and essentially the much larger solar wind velocity, both resulting in a much larger reconnection electric field $E_{\text {rec }}=V_{S W} B_{\text {south }}$ (Burton et al., 1975). For the 20 November storm, the source of its exceptional intensity is to be found only in the geometry and intensity of the magnetic cloud. Gopalswamy et al. (2005b) have shown that, on 20 November, the axial field of the magnetic cloud was stronger than expected from the above relation and pointing southward, which they interpret as two favourable conditions for a super-storm. The nevertheless strong magnetospheric response observed during the 29 May storm may have been driven - at least in part - by several factors. A series of three CMEs in short succession, the second possibly catching up with the third and thereby creating a particularly strong solar wind shock front, brought energy from several solar flares to the magnetopause where they arrived within a very short time interval. A prolonged period $(\sim 9 \mathrm{~h})$ of a strongly southward oriented interplanetary magnetic field (in excess of $10 \mathrm{nT}$ ) during the main phase of the event favoured solar wind-magnetosphere coupling.

The maximum values of the $\mathrm{Kp}$ and am magnetic indices agree with the $D_{s t}$ index to indicate the lower intensity of the May storm. In this context, it seems surprising to observe that the maximum $A E$ was the same during the May and November storms, and significantly smaller than during the October storms. This observation can be related to the stormsubstorm controversy (Iyemori and Rao, 1996; Kamide et al., 1998), the storm and substorm phenomena being usually related to the $D_{s t}$ and $A E$ indices, respectively. While it is generally agreed that particle injections in the storm-time ring current are related to the intensity of the convection and measured by the $D_{s t}$, the substorm activity is better characterised by the $A E$ index. In their discussion of the controversy, Daglis et al. (2003) have suggested that the DC part of the reconnection electric field could be responsible for the $D_{s t}$ while the fluctuating part generates substorms, thus explaining the non-proportionality of the magnetic indices.

The present study of the May 2003 storm and of its solar origin demonstrates that we still lack significant pieces in our chain of understanding. The fact that a magnetic cloud would eventually hit the magnetosphere was predictable, but its time of arrival could not be predicted. The temporal sequence of individual events during the storm period (such as the occurrence of substorms) was also qualitatively predictable, but not the timing of substorms or the intensity of the storm effects, neither from the observations nor from the models available to us. For example, the redistribution of the energy in the thermosphere was not very well predicted either from currently available models.

Possible improvement concerns the observational side where solar images from $\mathrm{SOHO}$ give us quite a lot but still incomplete information, due to the spacecraft location. The upcoming STEREO mission, which aims at resolving geometric ambiguities in the initiation and propagation of eruptive solar events, may help, at least for a limited period of optimal spacecraft constellation. It further concerns the modelling side where we do not have sufficiently good models of CME development, acceleration and propagation in the solar corona. We can neither predict the time of arrival at the Earth with the desired accuracy nor do we know enough about the magnetic conditions in the magnetic cloud. These conditions have important consequences for geospace since they control the transfer of magnetic flux and plasma energy and momentum from the solar wind into the magnetosphere. We also do not have sufficiently good models of magnetosphereionosphere-thermosphere interaction response in order to describe correctly the ultimate energy dissipation.

We conclude that we can often qualitatively understand and predict the impact of solar events on geospace, and we can predict that certain space weather effects are likely to occur. But we are still far from being able to provide quantitatively accurate predictions as far as the timing and the level of intensity of space storm and space weather effects are concerned.

Acknowledgements. We wish to thank the PIs of the experiments whose data are used in this study. SOHO is a mission of international cooperation between ESA and NASA. EIT, LASCO and MDI data have been used courtesy of EIT, LASCO, MDI consortia. THEMIS is operated on the island of Tenerife by the Centre National de la Recherche Scientifique/ Institut National des Sciences de l'Univers-Consiglio Nazionale delle Ricerche in the Spanish Observatory del Teide of the Istituto de Astrofisica. The authors are indebted to the GOES and BBSO teams for providing the employed data. ACE solar wind and IMF data were kindly provided by the SWEPAM and MAG instrument teams and the ACE Science Center. A. Fazakerley and D. Fontaine from the CLUSTER PEACE instruments are thanked for fruitful discussions. Geomagnetic indices have been provided by the Danish Meteorological Institute $(P C N)$, the World Data Center for Geomagnetism and Space Magnetism Kyoto, Japan $\left(A E, D_{s t}, \mathrm{SYM-H}\right.$ and ASY$\mathrm{H})$, the GeoForschungZentrum, Potsdam, Germany $(K p)$, and the Centre d'études des Environnements Terrestre et Planétaires, Saint Maur, France (am). The IMAGE magnetometer network is a joint Finnish-German-Norwegian-Polish-Swedish project. We thank the IMAGE PI, A. Viljanen (FMI), and O. Amm (on leave from FMI to STELAB, Nagoya University) for providing IMAGE data and computing equivalent ionospheric currents. EISCAT is an international association supported by the Research Councils of Finland (SA), France (CNRS), Germany (MPG), Japan (NIPR), Norway (NFR), Sweden (VR) and the United Kingdom (PPARC). The 
Finnish riometer chain is maintained by the Sodankylä Geophysical Observatory. The SuperDARN radar network is supported by National Institutions of participating countries. The CHAMP mission is supported by the German Space Agency (DLR) and operated by the GeoForschungZentrum in Postdam. CLS work is supported by ESA (Contract 16964/02/NL/LvH); CLS is part of the Space Weather NETwork (SWENET). This work is supported by French Institut National des Sciences de l'Univers (INSU) and CNES through the PNST (Programme National Soleil-Terre).

Topical Editor M. Pinnock thanks M. Hapgood and another referee for their help in evaluating this paper.

\section{References}

Araki, T.: A physical model of the geomagnetic sudden commencement, in: Solar Wind Sources of Magnetospheric Ultra-LowFrequency Waves, Geophys. Monogr. Ser., 81, 183-200, 1994.

Ballatore, P., Villain, J. P., Vilmer, N., and Pick, M.: Influence of the interplanetary medium on SuperDARN radar scattering occurrence, Ann. Geophys., 18, 1576-1583, 2001,

\section{SRef-ID: 1432-0576/ag/2000-18-1576.}

Barlier, F., Berger C., Falin, J. L., Kockarts, G., and Thuilier, G.: A thermospheric model based on satellite drag data, Ann. Geophys., 34, 9-4, 1978.

Berger, C., Biancale Ill, R., M., and Barlier, F.: Improvement of the empirical thermospheric model DTM: DTM94-comparative review on various temporal variations and prospects in space geodesy applications, J. Geod., 72, 161-178, 1998.

Brodrick, D., Tingay, S., and Wieringa, M.: X-ray magnitude of the 4 November 2003 solar flare inferred from the ionospheric attenuation of the galactic radio background, J. Geophys. Res., 110, A09S36, doi:10.1029/2004JA010960, 2005.

Brueckner, G. E., Howard, R. A., Koomen, M. J., Korendyke, C. M., Michels, D. J., Moses, J. D., Socker, D. J., Dere, K. P., Lamy, P. L., Llebaria, A., Bout, M. V., Schwenn, R., Simnett, G. M., Bedford, D. K., and Eyles, C. J.: The Large Angle Spectrographic Coronograph (LASCO), Solar Phys., 162, 357-402, 1995.

Bruinsma, S., Tamagnan, T., and Biancale, R.: Atmospheric densities derived from CHAMP/STAR accelerometer observations, Planet. Space Sci., 52, doi:10.1016/j.pss.2003.11.004, 2004.

Buonsanto, M. J. and Witasse, O.: An updated climatology of thermospheric neutral winds and $\mathrm{F}$ region ion drifts above Millstone Hill, J. Geophys. Res., 104, 24 675-24 687, 1999.

Burns, A. G., Killeen, T. L., Deng, W., Carignan, G. R., and Roble, R. G.: Geomagnetic storm effects in the low- to middlelatitude upper thermosphere, J. Geophys. Res., 100, 14673$14692,1995$.

Burton, R. K., McPherron, R. L., and Russel, C. T.: An empirical relationship between interplanetary conditions and Dst, J. Geophys. Res., 80, 4204-4214, 1975.

Chae, J., Moon, Y. J., and Park, Y. D.: Determination of magnetic helicity content of solar active regions from SOHO/MDI magnetograms, Solar Physics, 233, 39-55, 2004.

Coco, I., Amata, E., Marcucci, M. F., De Laurentis, M., Villain, J. P., Hanuise, C., and Candidi, M.: Effects on SuperDARN HF radar echoes of sudden impulses of solar wind dynamic pressure, Ann. Geophys., 23, 1-13, 2005,

SRef-ID: 1432-0576/ag/2005-23-1.

Cornilleau-Wehrlin, N., Chanteur, G., Perraut, S., Rezeau, L., Robert, P., Roux, A., Villedary, C. de, Canu, P., Maksimovic, M., de Conchy, Y., Hubert, D., Lacombe, C., Lefeuvre, F., Par- rot, M., Pincon, J. L., Decreau, P. M. E., Harvey, C. C., Louarn, P., Santolik, O., Alleyne, H. StC., Roth, M., Chust, T., Le Contel, O., and STAFF team: First results obtained by the Cluster STAFF experiment, Ann. Geophys., 21, 437-456, 2003, SRef-ID: 1432-0576/ag/2003-21-437.

Daglis, I. A., Kozyra, J. U., Kamide, Y., Vassiliadis, D., Sharma, A. S., Liemohn, M. W., Gonzalez, W. D., Tsurutani, B. T., and Lu, G.: Intense space storms: critical issues and open disputes, J. Geophys. Res., 108(A5), 1208, doi:10.1029/2002JA009722, 2003.

Davis, T. N. and Sugiura, M.: Auroral electrojet activity index AE and its universal time variation, J. Geophys. Res., 71, 785-801, 1966.

Delaboudinière, J.-P., Artzner, G. E., Brunaud, J., Gabriel, A. H., Hochedez, J. F., Millier, F., Song, X. Y., Au, B., Dere, K. P., Howard, R. A., Kreplin, R., Michels, D. J., Moses, J. D., Defise, J.-M., Jamar, C., Rochus, P., Chauvineau, J. P, Marioge, J. P., Catura, R. C., Lemen, J. R., Shing, L., Stern, R. A., Gurman, J. B., Neupert, W. M., Maucherat, J., Clette, F., Cugnon, P., and Van Dessel, E. L.: EIT : Extreme-Ultraviolet Imaging Telescope for the SOHO mission, Solar Physics, 162, 291-312, 1995.

Delannée, C., Delaboudinière, J. P., and Lamy P.: Observation of the origin of CMEs in the low corona, Astron. And Astrophys., 335, 725-742, 2000.

Emery, B. A., Lathuillere, C., Richards, P. G., Roble, R. G., Buonsanto, M. J., Knipp, D. J., Wilkinson, P., Sipler, D. P., and Niciejewski, R.: Time dependent thermospheric neutral response to the 2-11 November 1993 storm period, J. Atmos. Solar-Terr. Phys., 61, 329-350, 1999.

Feldstein, Y. J., Pisarsky, V. Yu., Rudneva, N. M., and Grafe, A.: Ring current simulation in connection with interplanetary space conditions, Planet. Space Sci., 32, 975-984, 1984.

Förster, M. and Jakowski, N.: Geomagnetic Storm Effects on the Topside Ionosphere and Plasmasphere: A Compact Tutorial and New Results, Surveys in Geophysics, 21, 47-87, 2000.

Fuller-Rowell, T. J., Codrescu, M. V., Roble, R. G., and Richmond, A. D.: How does the thermosphere and ionosphere react to a geomagnetic storm?, Magnetic Storms, Geophysical Monograph Series, Vol. 98., edited by: Bruce, T., Tsurutani, B. T., Gonzalez, W. D., Kamide, Y., and Arballo, J. K., Washington D.C.: American Geophysical Union, 203-225, 1997.

Gilbert, H. C., Holzer, T. E., Thompson, B. J., and Burkepile, T.: A comparison of CME-associated atmospheric waves observed in coronal (FeXII $195 \alpha$ ) and chromospheric (HeI $10830 \alpha$ ) lines, Astrophys. J., 607, 540-553, 2004.

Gonzalez, W. D., Tsurutani, B. T., Gonzalez, A. L. C., Smith, E. J., Tang, F., and Akasofu, S.-I.: Solar wind-magnetosphere coupling during intense magnetic storms (1978-1979), J. Geophys. Res., 94, 8835-8851, 1989.

Gonzalez, W. D., Joselyn, J. A., Kamide, K., Kroehl, H. W., Rostoker, G., Tsurutani, B. T., and Vasyliunas, V. M.: What is a geomagnetic storm, J. Geophys. Res., 99, 5771-5792, 1994.

Gonzalez, W. D., Clua de Gonzalez, A. L., Dal Lago, A., Tsurutani, B. T., Arballo, J. K., Lakhina, G. K., Buti, B., Ho, C. M., and Wu, S. T., Magnetic cloud field intensities and solar wind velocities, Geophys. Res. Lett., 25, 963-966, 1998.

Gonzalez, W. D., Tsurutani, B. T., and Gonzalez, A. L. C.: Interplanetary origin of geomagnetic storms, Space Sci. Rev., 88, 529-562, 1999.

Gopalswamy, N., Lara, A., Lepping, R. P., Kaiser, M. L., Berdichevsky, D., and St. Cyr, O. C.,: Interplanetary acceleration of Coronal Mass Ejections, Geophys. Res. Lett., 27, 145- 
$148,2000$.

Gopalswamy, N., Barbieri, L., Lu, G., Plunkett, S. P., and Skoug, R. M.: Introduction to the special section: Violent Sun-Earth connection events of October-November 2003, Geophys. Res. Lett., 32, L03S01, doi:10.1029/2005GL022348, 2005a.

Gopalswamy, N., Yashiro, S., Michalek, G., Xie, H., Lepping, R. P., and Howard, R. A.: Solar source of the largest geomagnetic storm of cycle 23, Geophys. Res. Lett., 32, L12S09, doi:10.1029/2004GL021639, 2005b.

Gosling, J. T.: The solar flare myth, J. Geophys. Res, 98, $18937-$ $18949,1993$.

Hedin, A. E.: Extension of the MSIS thermosphere model into the middle and lower thermosphere, J. Geophys. Res., 96, 11591172, 1991.

Ijima, T. and Potemra, T. A.: The relationship between interplanetary quantities and Birkeland current densities, Geophys. Res. Lett., 9, 442-445, 1982.

Iijima, T., Potemra, T. A., Zanetti, L. J., and Bythrow, P.F.: Large-scale Birkeland currents in the dayside polar region during strongly northward IMF: A new Birkeland current system, J. Geophys. Res., 89, 7441-7452, 1984.

Iyemori, T. and Rao, D. R. K.: Decay of the $D_{s t}$ field of geomagnetic disturbance after substorm onset and its implication to storm-substorm relation, Ann. Geophys., 14, 608-618, 1996,

\section{SRef-ID: 1432-0576/ag/1996-14-608.}

Jakowski, N.: TEC Monitoring by Using Satellite Positioning Systems, Modern Ionospheric Science, edited by: Kohl, H., Rüster, R., and Schlegel, K., EGS, Katlenburg-Lindau, ProduServ GmbH Verlagsservice, Berlin, 371-390, 1996.

Johnstone, A. D., Alsop, C., Burge, S., Carter, P. J., Coates, A. J., Coker, A. J., Fazakerley, A. N., Grande, M., Gowen, R. A., Gurgiolo, C., Hancock, B. K., Narheim, B., Preece, A., Sheather, P. H., Winningham, J. D., and Woodliffe, R. D.: Peace: A Plasma Electron and Current Experiment, Space Sci. Rev. 79, 351-398, 1997.

Kamide, Y., Baumjohann, W., Daglis, I. A., Gonzalez, W. D., Grande, M., Joselyn, J. A., McPherron, R. L., Phillips, J. L., Reeves, E. D. G., Rostoker, G., Sharma, A. S., Singer, H. ., Tsurutani, B. T., and Vasyliunas, V. M.: Current understanding of magnetic storms: storm-substorm relationships, J. Geophys. Res, 103, 17 705-17 728, 1998.

Knipp, D. J., Welliver, T., McHarg, M. G., Chun, F. K., Tobiska, W. K., and Evans, D.: Climatology of extreme upper atmospheric heating events, Adv. Space Res., in press, 2005.

Lathuillère, C. and Menvielle, M.: WINDII thermosphere temperature perturbation for magnetically active situations, J. Geophys. Res., 109, A11304, doi:10.1029/2004JA010526, 2004.

Le, G., Russel, C. T., and Luhmann, J. G.: POLAR magnetic observations of the low-altitude magnetosphere during the January 1997 coronal mass ejection/magnetic cloud event, Geophys. Res. Lett., 25, 2533-2536, 1998.

Li, W., Raeder, J., Dorelli, J., Øieroset, M., and Phan, T. D.: Plasma sheet formation during long period of northward IMF, Geophys. Res. Lett., 32, L12S08, doi:10.1029/2004GL021524, 2005.

Mersmann, U., Baumjohann, W., Küppers, F., and Lange, K.: Analysis of an eastward electrojet by means of upward continuation of ground-based magnetometer data, J. Geophys. Res., 45, 281298, 1979.

Øieroset, M., Raeder, J., Phan, T. D., Wing, S., McFadden, J. P., Li, W., Fujimoto, M., Rème, H., and Balogh, A.: Global cooling and densification of the plasma sheet during an extended period of purely northward IMF on October 22-24, 2003, Geophys. Res.
Lett., 32, L12S07, doi:10.1029/2004GL021523, 2005.

Palmroth, M., Pulkkinen, T. I., Janhunen, P., McComas, D. J., Smith, C. W., and Koskinen, H. E. J. : Role of solar wind dynamic pressure in driving ionospheric Joule heating, J. Geophys. Res., 109, A11302, doi:10.1029/2004JA010529, 2004.

Picone, J. M., Hedin, A. E., Drob, D. P., and Aikin, A. C.: NRLMSISE-00 empirical model of the atmosphere: Statistical comparisons and scientific issues, J. Geophys. Res., 107(A12), 1468, doi:10.1029/2002JA009430, 2002.

Popov, V. A., Papitashvili, V. O., and Watermann, J. F.: Modeling of equivalent ionospheric currents from meridian magnetometer chain data, Earth Planets Space, 53, 129-137, 2001.

Potemra, T. A.: Sources of large-scale Birkeland currents, in: Physical signatures of magnetospheric boundary layer processes, edited by: Holtet, J. A. and Egeland, A., NATO Advanced Science Institutes Series, Vol. 425, 1994.

Prölss, G. W., Brace, L. H., Mayr, H. G., Carignan, G. R., Killeen, T. L., and Klobuchar, J. A.: Ionospheric Storm Effects at Subauroral Latitude: A Case Study, J. Geophys. Res., 96, 1275-1288, 1991.

Ranta, H., Ranta, A., Collis, P. N., and Hargreaves, J. K.: Development of the auroral absorption substorm: studies of preonset phase and sharp onset using an extensive riometer network, Planet. Space Sci., 29, 1287-1313, 1981.

Reigber, C., Schwintzer, P., and Lühr, H.: The CHAMP geopotential mission, Boll. Geof. Teor. Appl., 40, 285-289, 1999.

Sardón, E., Rius, A., and Zarraoa, N.: Estimation of the receiver differential biases and the ionospheric total electron content from Global Positioning System observations, Radio Sci., 29, 577586, 1994.

Scherrer, P. H., Bogart, R. S., Bush, R. I., Hoeksema, J. T., Kosovichev, A. G., Schou, J., Rosenberg, W., Springer, L., Tarbell, T. D., Title, A., Wolfson, C. J., Zayer, I., and the MDI engineering team: The Solar Oscillation Investigation - Michelson Doppler Imager, Solar Phys., 162, 129-188, 1995.

Schmieder, B., van Driel-Gesztelyi, L., Aulanier, G., Démoulin, P., Thompson, B., De Forest, C., Wiik, J. E., St. Cyr, C., and Vial, J. C.: Relationships between CME's and prominences, Adv. Space Res., 29, 1451-1460, 2002.

Shue, J.-H. and Kamide, Y.: Effects of solar wind density on auroral electrojets, Geophys. Res. Letters, 28, 2181-2184, 2001.

Sibeck, D. G., Lopez, R. E., and Roelof, R. C.: Solar wind control of the magnetopause shape, location, and motion, J. Geophys. Res., 96, 5489-5495, 1991.

St. Cyr, O. C., Howard, R. A., Sheeley, N. R. J. R., Plunkett, S. P., Michels, D. J., Paswaters, S. E., Koomen, M. J., Simnett, G. M., Thompson, B. J., Gurman, J. B., Schwenn, R., Webb, D. F., Hildner, E., and Lamy, P. L.: Properties of Coronal Mass Ejections: SOHO LASCO observations from January 1996 to June 1998, J. Geophys. Res., 105, 18 169-18 186, 2000.

Sugiura, M.: Hourly values of equatorial Dst index for the IGY, Ann. Int. Geophys. Year, 35, 9-45, 1965.

Sugiura, M. and Kamei, T.: Equatorial Dst index, 1957-1986, edited by: Berthelier, A. and Menvielle, M., IAGA Bulletin 40, ISGI Publ. Off. Saint Maur, $246,1991$.

Tavernier, G., Granier, J. P., Jayles, C., Sengenes, P., and Rozo, F.: The current evolutions of the DORIS system, Adv. Space Res., 31, 1947-1952, 2003.

Thompson, B. J., Gurman, J. B., Neupert, W. M., Newmark, J. S., Delaboudinière, J.-P., St. Cyr, O. C., Stezelberger, S., Dere, K. P., Howard, R. A., and Michels, D. J.: SOHO/EIT observations of the 1997 April 7 coronal transient: possible evidence of coronal 
Moreton waves, Ap. J., 517, L151-L154, 1999.

Thomson, N. R., Rodger, C. J., and Dowden, R. L.: Ionosphere givessize of greatest solar flare, Geophys. Res. Lett., 31, L06803, doi:10.1029/2003GL019345, 2004.

Troshichev, O. A., Dmitrieva, N. P., and Kuznetsov, B. M.: Polar cap magnetic activity as a signature of substorm development, Planet. Space Sci., 27, 217-221, 1979.

Troshichev, O. A., Andrezen, V. G., Vennerstrøm, S., and FriisChristensen, E.: Magnetic activity in the polar cap - A new index, Planet. Space Sci., 36, 1095-1102, 1988.

Tsurutani, B. T., Gonzalez, W. D., Gonzalez, A. L. C., Tang, F., Arballo, J. K., and Okada, M.: Interplanetary origin of geomagnetic activity in the declining phase of the solar cycle, J. Geophys. Res., 100, 21 717-21 733, 1995.

Tsurutani, B.T. and Gonzalez, W. D.: The interplanetary causes of magnetic storms: a review, in: Magnetic Storms, edited by: Tsurutani, B. T., Gonzalez, W. D., Kamide, Y., and Arballo, J. K., Geophysical Monograph Series, Vol. 98, Washington D.C., American Geophysical Union, 77-89, 1997.

Untiedt, J. and Baumjohann, W.: Studies of polar current systems using the IMS Scandinavian magnetometer array, Space Sci. Rev., 63, 245-390, 1993.

Viljanen, A. and Häkkinen, L.: IMAGE magnetometer network, in: Satellite-Ground Based Coordination Sourcebook, edited by: Lockwood, M., Wild, M. N., and Opgenoorth, H. J., ESA SP1198, 111-117, 1997.
Vilmer, N., Pick, M., Schwenn, R., Ballatore, P., and Villain, J. P.: On the solar origin of interplanetary disturbances observed in the vicinity of the Earth, Ann. Geophys., 21, 847-862, 2003, SRef-ID: 1432-0576/ag/2003-21-847.

Wilhjelm, J. E., Friis-Christensen, J. E., and Potemra, T.: The relationship between ionospheric and field-aligned current in the dayside cusp, J. Geophys. Res., 83, 5586-5594, 1978.

Witasse, O., Lilensten, J., Lathuillère, C., and Pibaret, B.: Meridional thermospheric neutral wind at high latitude over a full solar cycle, Ann. Geophys., 16, 1400-1409, 1998,

SRef-ID: 1432-0576/ag/1998-16-1400.

Woods, T. N., Epavier, F. G., Fontenla, J., Harder, J., Knopp, G., McClintock, W. E., Rottman, G., Smiley, B., and Snow, M.: Solar irradiance variability during the October 2003 solar storm period, Geophys. Res. Lett., 31, L10802, doi:10.1029/2004GL019571, 2004.

Zhou, X. and Tsurutani, B. T.: Rapid intensification and propagation of the dayside aurora: Large- scale interplanetary pressure pulses (fast shocks), Geophys. Res. Lett., 26, 1097-1100, 1999.

Zhukov, A. N. and Auchère, F.: On the nature of EIT waves, EUV dimmings and their links to CMEs, Astron. And Astrophys., 427, 705-716, 2004. 